Article

\title{
Experimental and Numerical Investigation of an Innovative Method for Strengthening Cold-Formed Steel Profiles in Bending throughout Finite Element Modeling and Application of Neural Network Based on Feature Selection Method
}

\author{
Ehsan Taheri ${ }^{1, *}$, Saeid Esgandarzadeh Fard ${ }^{2}$, Yousef Zandi ${ }^{2}$ (D) and Bijan Samali ${ }^{1}$ \\ 1 Centre for Infrastructure Engineering, Western Sydney University, Kingswood, Sydney, NSW 2747, Australia; \\ b.samali@westernsydney.edu.au \\ 2 Department of Civil Engineering, Tabriz Branch, Islamic Azad University, Tabriz 5157944533, Iran; \\ stu.saeid.esgandarzadeh@iaut.ac.ir (S.E.F.); zandi@iaut.ac.ir (Y.Z.) \\ * Correspondence: e.taheri@westernsydney.edu.au
}

Citation: Taheri, E.; Esgandarzadeh Fard, S.; Zandi, Y.; Samali, B. Experimental and Numerical Investigation of an Innovative Method for Strengthening Cold-Formed Steel Profiles in Bending throughout Finite Element Modeling and Application of Neural Network Based on Feature Selection Method. Appl. Sci. 2021, 11, 5242 https://doi.org/10.3390/app11115242

Academic Editor: José A. F. O. Correia

Received: 7 May 2021

Accepted: 1 June 2021

Published: 4 June 2021

Publisher's Note: MDPI stays neutral with regard to jurisdictional claims in published maps and institutional affiliations.

Copyright: (C) 2021 by the authors Licensee MDPI, Basel, Switzerland. This article is an open access article distributed under the terms and conditions of the Creative Commons Attribution (CC BY) license (https:// creativecommons.org/licenses/by/ $4.0 /)$.
Abstract: This study evaluates an innovative reinforcement method for cold-formed steel (CFS) upright sections through finite element assessment as well as prediction of the normalized ultimate load and deflection of the profiles by artificial intelligence (AI) and machine learning (ML) techniques. Following the previous experimental studies, several CFS upright profiles with different lengths, thicknesses and reinforcement spacings are modeled and analyzed under flexural loading. The finite element method (FEM) is employed to evaluate the proposed reinforcement method in different upright sections and to provide a valid database for the analytical study. To detect the most influential factor on flexural strength, the "feature selection" method is performed on the FEM results. Then, by using the feature selection method, a hybrid neural network (a combination of multi-layer perceptron algorithm and particle swarm optimization method) is developed for the prediction of normalized ultimate load. The correlation coefficient (R), root mean square error (RMSE), Nash-Sutcliffe efficiency (NSE), mean absolute error (MAE) and Wilmot's index of agreement (WI) are used as the measure of precision. The results show that the geometrical parameters have almost the same contribution in the flexural capacity and deflection of the specimens. According to the performance evaluation indexes, the best model is detected and optimized by tuning other algorithm parameters. The results indicate that the hybrid neural network can successfully predict the normalized ultimate load and deflection.

Keywords: cold-formed steel; upright; finite element method; feature selection method; multi-layer perceptron; particle swarm optimization; neural network

\section{Introduction}

Employing cold-formed steel (CFS) racking systems has been extensively developed around the world due to their valuable structural benefits and workability, especially for storage and warehouse applications [1]. In recent years, various researchers and engineers have investigated different approaches to enhance the overall performance of these systems by utilizing different CFS upright strengthening methods.

In this regard, many studies indicated that CFS racking systems under flexural loading experience different types of failures, including distortional buckling failure modes [2], which can affect the stability status of upright frames [3]. Various studies worked to improve different characteristics of uprights not only to enhance the bearing capacity, but also to extend the application of these systems. Following the study of racking system performances, Put et al. [4] applied a series of eccentrically and concentrically loading on the CFS upright connections and reported that by increasing the eccentricity, the beams strength decreases. Wang and Young [5] investigated novel CFS channel sections with double and single stiffeners and showed that local and distortional buckling can be controlled using 
this method. In another study, Calderoni et al. [6] conducted a series of monotonic and cyclic experiments on CFS members. Their results indicated that the CFS channels could not resist the buckling deformations due to the lack of flexural stiffness. Wang and Zhang [7] studied C-shaped CFS elements with or without edge stiffeners. They employed two types of stiffeners and reported an increase in the capacity of CFS members due to applying stiffeners. Taheri et al. [8] evaluated the influence of a new reinforcement approach on the compressive capacity of racking upright profiles. In another study, Taheri et al. [9] also performed a series of flexural tests on CFS sections with or without the reinforcement approach. The results indicated that the proposed reinforcements considerably improved the ultimate flexural capacity.

The expensive and time-consuming nature of actual experimental tests has encouraged researchers to employ other types of approaches for structural evaluations, such as numerical methods. Since the finite element method (FEM) has major priorities in comparison to other numerical approaches, employing this technique has drastically increased for a variety of engineering problems, especially CFS racking systems. Visy et al. [10] numerically studied the flexural behavior of stiffened CFS slotted beams subjected to different loading scenarios. Nandini and Kalyanaraman [11], in a numerical investigation, studied the behavior and strength of Lipped channel beams of various lengths. They suggested an approach to design these beams under the interaction of local, distortional and overall lateral-torsional buckling based on the Euro code provisions. There are several other studies in the literature that simulated the behavior and strength of CFS racking frames through FEM [12-14].

Artificial intelligence is a group of techniques related to intelligent methods that consider each problem with a defined intelligence algorithm. Most of the applications of these techniques in engineering problems are focused on either predicting or verifying a problem. Prediction accuracy depends on a variety of variables, such as error, soft computing approach, estimation of the problems before the prediction process, etc. Backpropagation (BP) approaches, which are considered among classic techniques, are generally proposed to train artificial neural networks (ANN). Machine learning is another type of these algorithms that benefits from a learning circuit. Some of the rotational properties of CFS racking systems have been successfully estimated by the machine learning method in the past years [15]. In order to address classic algorithm deficiencies, some approaches, including genetic algorithm (GA) [16], particle swarm optimization (PSO) [17], and multi-layer perceptron (MLP) [18], have been proposed and utilized in different prediction cases in recent years. Generally, the PSO algorithm has been proved as a reliable technique to be combined with other types of intelligence algorithms based on different studies $[19,20]$.

In this paper, the proposed reinforcement method for CFS uprights (previously presented by the authors $[8,9])$ is further investigated through FEM and machine learning algorithms. First, a finite element model is developed in ABAQUS software to simulate and analyze the CFS upright frames under flexural loading. Then, the FEM results are compared and verified by the experimental test data in the literature [9]. Thereafter, the verified FEM is employed for a parametric study to evaluate the performance of upright frames with different lengths, thicknesses and reinforcement spacing. Considering the FEM and test results (current study and test results in [9]), an artificial intelligence approach is also employed both for predicting the flexural capacity of the proposed system and verifying the FEM models. First, a feature selection based algorithm is used to find the most governing property of flexural strength and then a hybrid neural network (MLP algorithm in combination with PSO) is utilized for verification, optimization and prediction.

\section{Finite Element Modeling}

The proposed reinforcement method for strengthening the upright frame, which was previously discussed by Taheri et al. [8,9], is presented in Figure 1. In this paper, a parametric FE study is conducted on the proposed reinforcement system to obtain a reliable database for the artificial intelligence approach. All of the FE modeling is conducted in 
the ABAQUS computer program. First, the FE modeling approach is presented in detail (Sections 2.1-2.4) and then it is verified by the experimental data (Section 2.5) [9]. Finally, the validated FE method is utilized for a parametric study (Section 2.6). The parametric study evaluates the influence of various reinforcement spacing, including 50, 100, 150, 250, and $300 \mathrm{~mm}$, on the strength of the profiles with different thicknesses of 1.6, 2, 2.5 and $3 \mathrm{~mm}$. Moreover, in order to achieve a comprehensive dataset, different upright lengths are taken into account in this study. The details of the FE models are provided in Table 1 and Figure 1. Further details about the experimental setup, specimen specifications, etc., can be found in $[8,9]$.

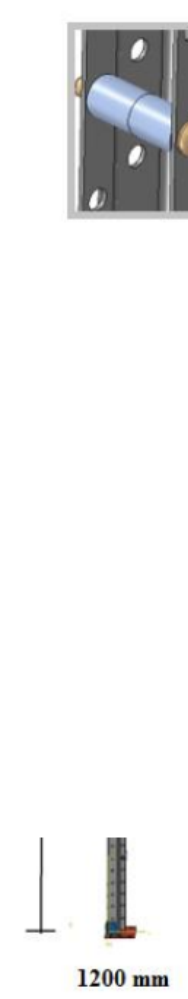

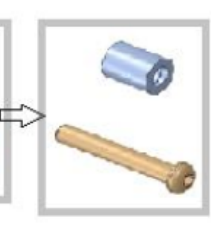

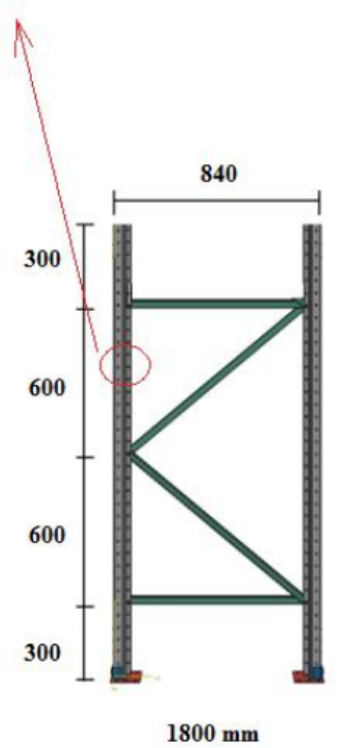

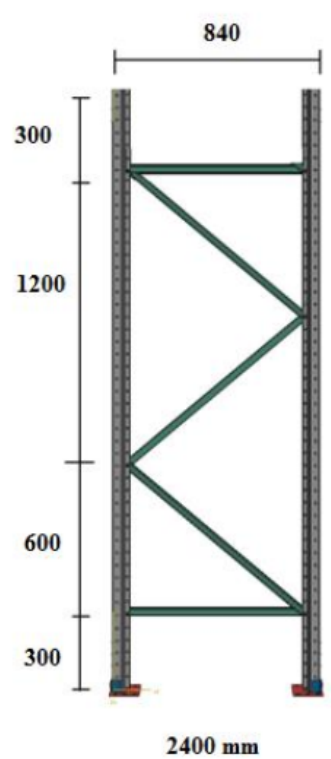
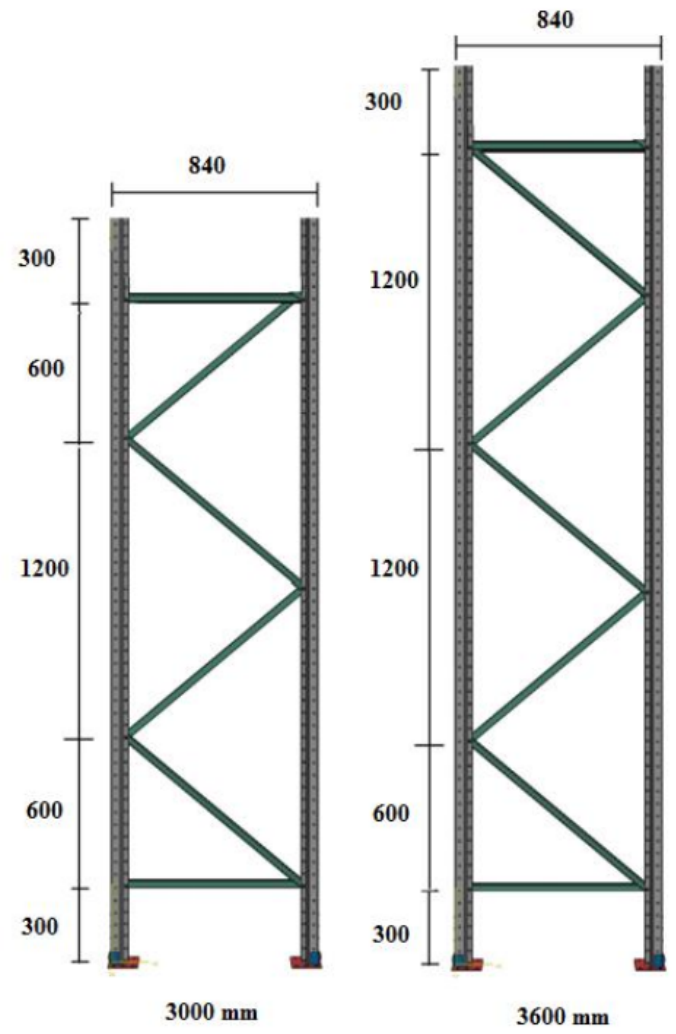

Figure 1. Schematic of models.

Table 1. Geometrical features of models.

Upright Length (mm)

Upright Thickness (mm)

Reinforcement Spacing (mm)

\section{0}

100

150

200

250

300

\subsection{Material Properties}

The Poisson's ratio and the modulus of elasticity are assumed to be 0.3 and $200 \mathrm{GPa}$, respectively [21]. Additionally, other material properties were captured according to the actual coupon test, which is indicated in Figure 2 and Table 2. The material law of the frame assembly was modeled using the bi-linear stress-strain relation [21]. 


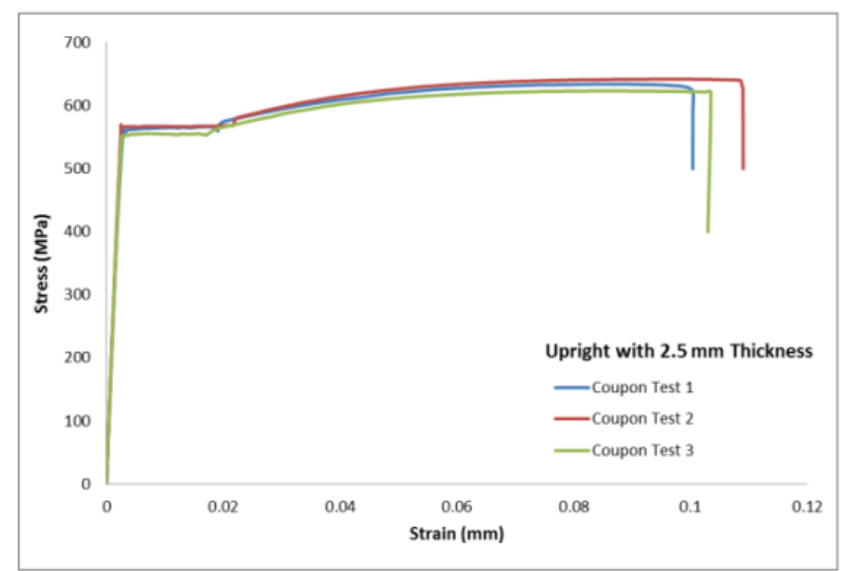

(a)

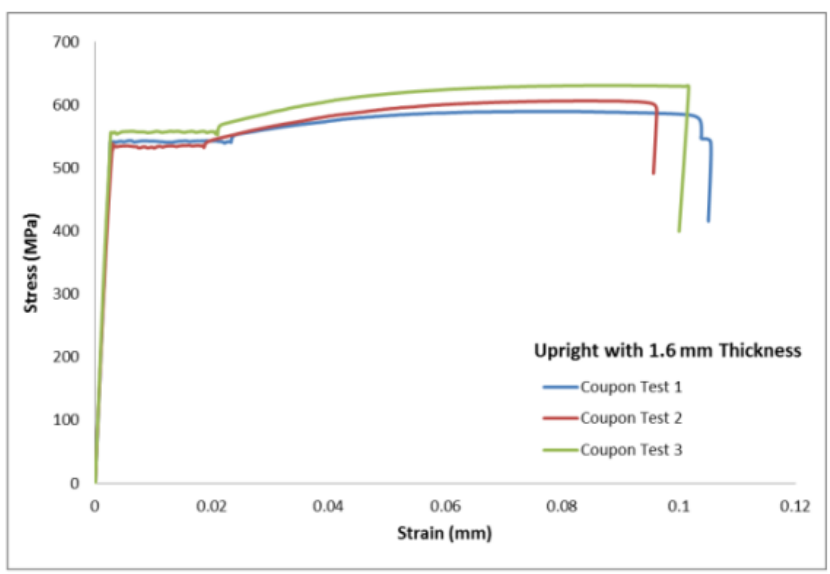

(b)

Figure 2. Coupon test results for uprights: (a) with $1.6 \mathrm{~mm}$, and (b) with $2.5 \mathrm{~mm}$ thickness [9].

Table 2. Material properties of upright sections.

\begin{tabular}{cccc}
\hline Thickness $(\mathbf{m m})$ & Yield Stress, fy (MPa) & Ultimate Stress, fu (MPa) & Elongation (\%) \\
\hline 2.5 & 572 & 608 & 13 \\
\hline 1.6 & 563 & 591 & 11 \\
\hline
\end{tabular}

\subsection{Connections and Interactions}

The penalty method with a surface-to-surface interaction is employed for models, where a friction coefficient of 0.3 is considered for the tangential response [21-23]. Hard contact is also adopted for normal behavior. For simulating the interaction of bolts, the coupling method is employed. A reference point is defined at the center of the bolt hole and then the end beam restraints are considered as a beam, using the contact pairs between the elements at the two opposite sides of the built-up sections. Figure 3 shows the existing interactions between the bending frame components model.

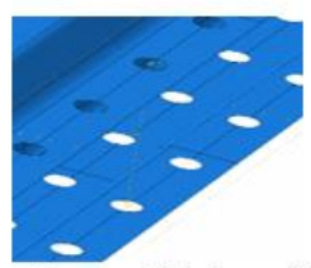

Interaction of brace with bolt modelling using coupling and beam connector

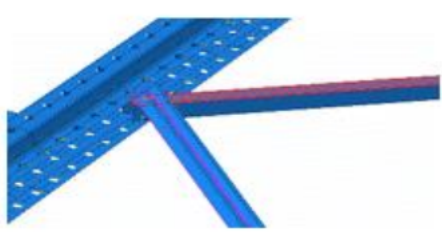

Interaction of two braces

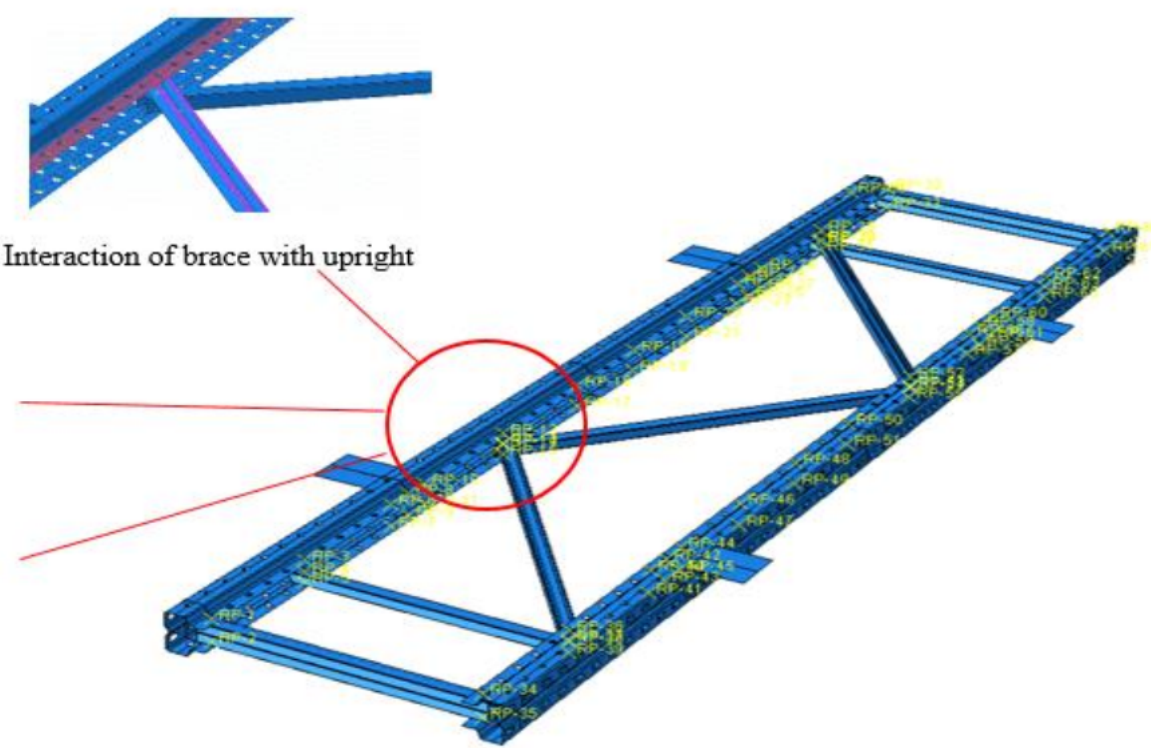

Figure 3. Interactions between frame elements. 


\subsection{Boundary Conditions and Loading}

All boundary components are constrained to simulate the test setup illustrated in Figure 4. The vertical translation on the supports is restrained. The concentrated load with the displacement method is applied at the shear center of the upright section on the loading plates, while the rotations and translation are allowed to simulate the actual test conditions. Details of the test setup about each axis is illustrated in Figure 4 [9].

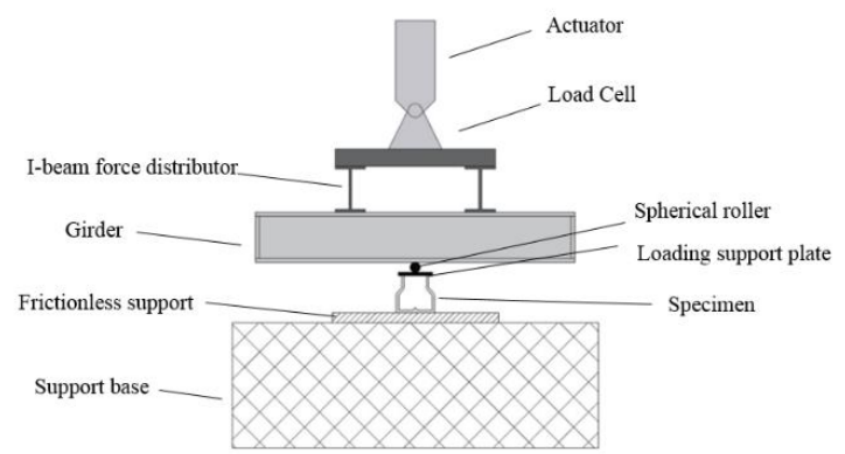

(a)

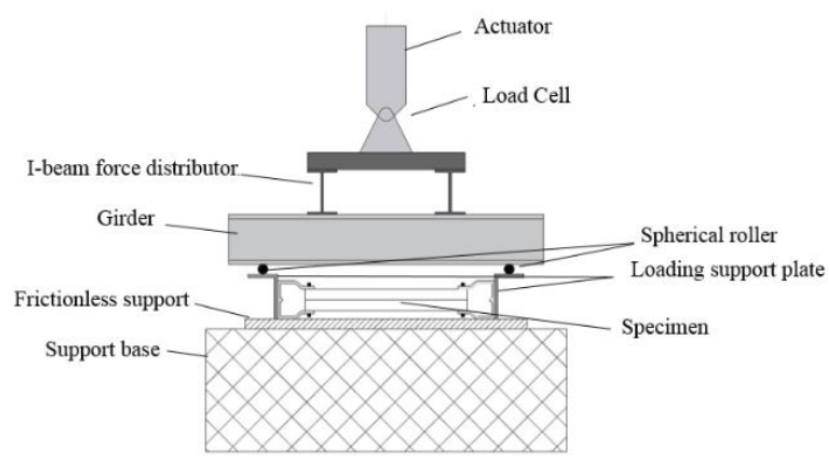

(b)

Figure 4. (a) Minor axis test setup. (b) Major axis test setup [9].

\subsection{Mesh}

In this paper, shell elements are deployed since the thickness of the open CFS members is very small in comparison with their width and length; thus, buckling deformations can be explicitly modeled. The four-node shell element with reduced integration (S4R) is employed to model the frame elements [24]. A convergence study is performed to capture the optimum mesh size for the upright and bracing members, and it is observed that quad-dominated meshes with dimensions of $10 \mathrm{~mm}$ are deemed satisfactory for frame elements. Figure 5 shows the final mesh used for the upright models.

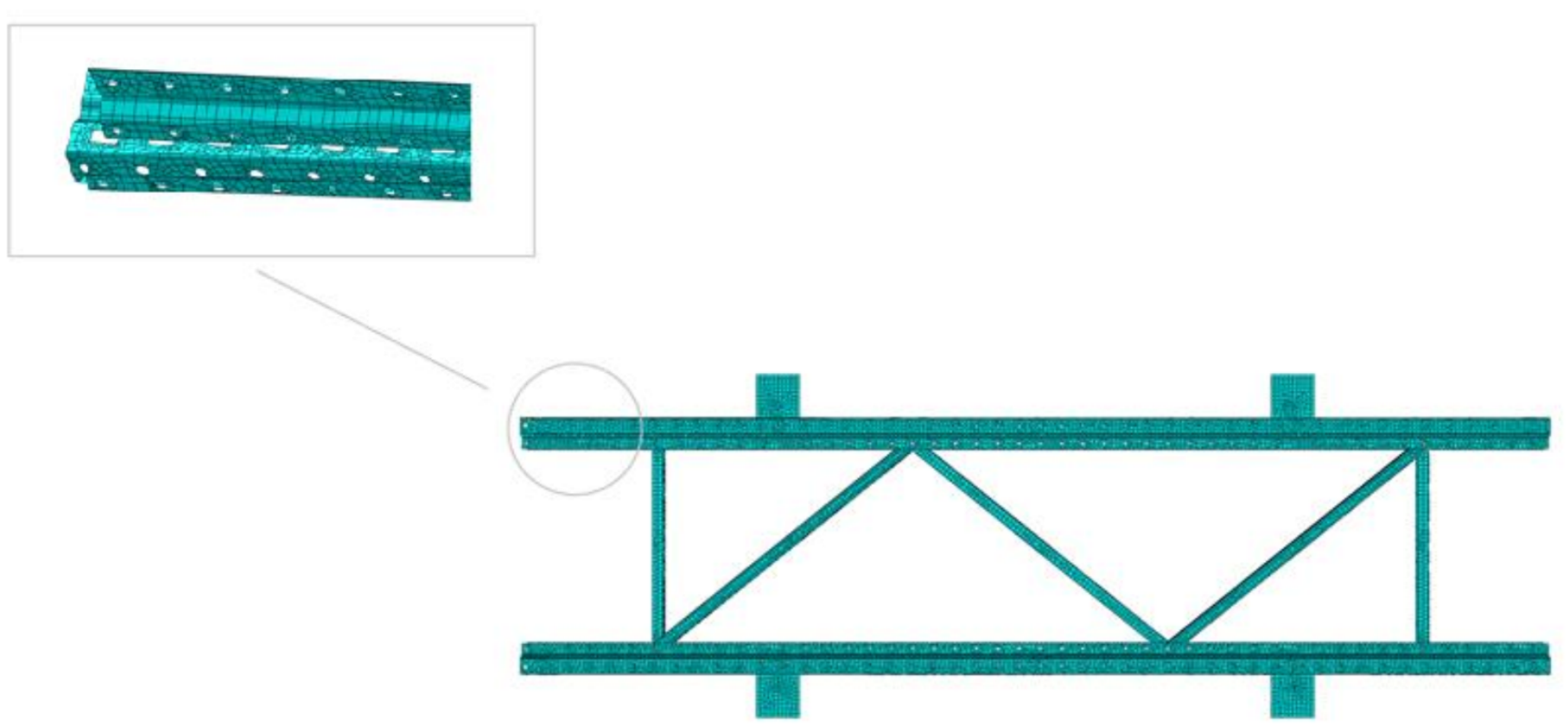

Figure 5. Typical FE mesh of an upright section. 


\subsection{FE Model Verification}

After establishing the FE models, a loading simulation is conducted through the ABAQUS program. It should be noted that only specimens with $2400 \mathrm{~mm}$ length and $1.6 \mathrm{~mm}$ thickness are employed for the verification purpose. In addition, three scenarios of non-reinforcement, reinforcement with $200 \mathrm{~mm}$ spacing, and reinforcement with $300 \mathrm{~mm}$ spacing are considered. In this part, linear regression analyses are applied to the FE results to assist in validating the obtained results of the numerical models. Additionally, the verified results are exported to a database for artificial intelligence applications, which will be discussed in Section 3.

\subsubsection{Verification under Minor Axis Loading}

In order to illustrate the accuracy of the FEM results, each curve is compared with the corresponding test curve and a linear regression is drawn for each model [25]. Figure 6 compares the normalized bending moment-deflection curves between the FE and experimental results. In addition, Figure 7 shows the linear regression of the FEM curve with the experimental curve. Table 3 demonstrates the evaluation criteria of the accuracy of the FEM predictions. Comparison of the experimental and numerical results indicates the outstanding accuracy and compatibility between the two methods.

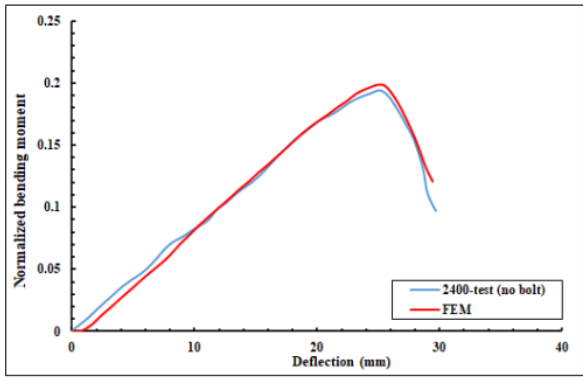

(a)

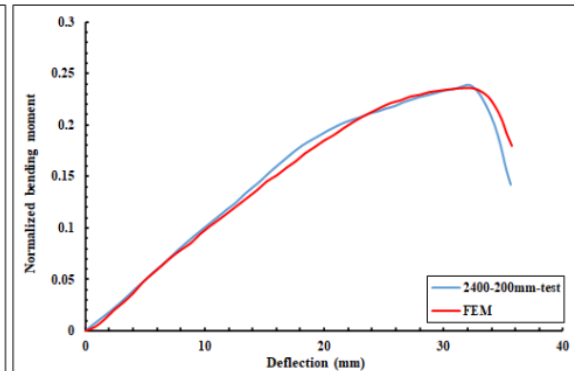

(b)

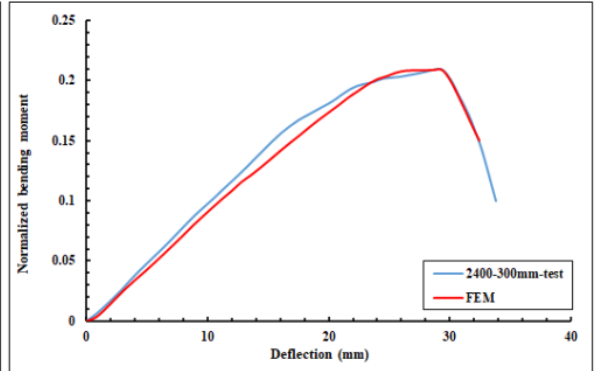

(c)

Figure 6. Comparison of the FE model against the minor-axis test results for (a) non-reinforced model, (b) $200 \mathrm{~mm}$ reinforced model and (c) $300 \mathrm{~mm}$ reinforced model.

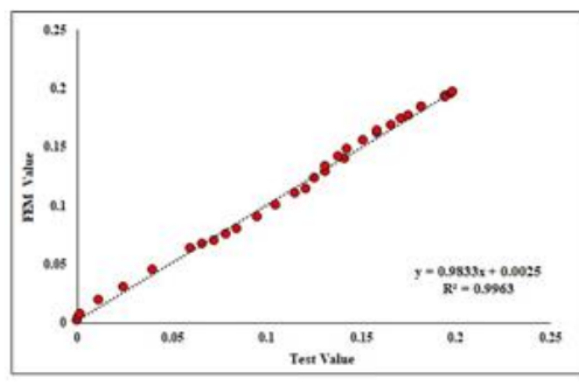

(a)

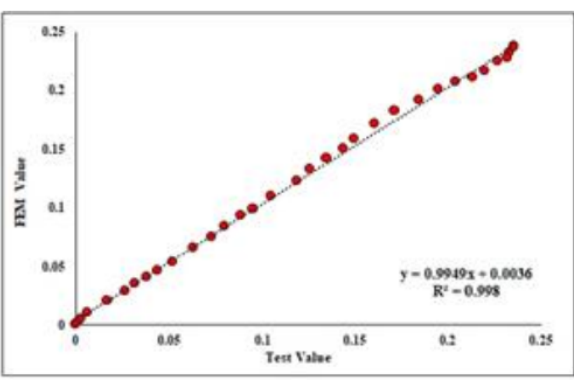

(b)

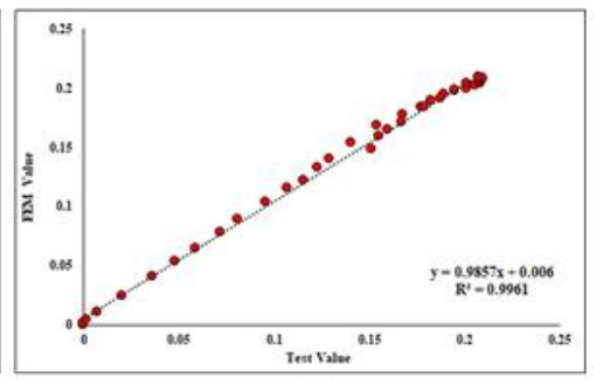

(c)

Figure 7. Linear regression diagram for (a) non-reinforced model, (b) $200 \mathrm{~mm}$ reinforced model, and (c) $300 \mathrm{~mm}$ reinforced model.

\subsubsection{Verification under Major Axis Loading}

The same technique is also employed for the FE assessment of the upright section under the major axis loading. Figure 8 compares the normalized bending moment-deflection curve between the FEM and experimental results of the upright section under major axis loading. Figure 9 also indicates the linear regression of the FE results with the experimental curve. The evaluation criteria for the accuracy of the FEM predictions are represented in Table 4. Based on Figure 9 and Table 4, the FEM results indicate high accuracy and compatibility with the experimental results. 
Table 3. FEM vs. experimental results accuracy details in terms of evaluation criteria.

\begin{tabular}{|c|c|c|}
\hline \multirow{4}{*}{ Non-reinforced model } & \multicolumn{2}{|c|}{ Evaluation criteria } \\
\hline & Std * & 0.0619 \\
\hline & Pearson (r) & 0.9981 \\
\hline & $\mathrm{R}^{2}$ & 0.9963 \\
\hline \multirow{4}{*}{$200 \mathrm{~mm}$ reinforced model } & \multicolumn{2}{|c|}{ Evaluation criteria } \\
\hline & Std & 0.0803 \\
\hline & Pearson (r) & 0.9937 \\
\hline & $\mathrm{R}^{2}$ & 0.998 \\
\hline \multirow{4}{*}{$300 \mathrm{~mm}$ reinforced model } & \multicolumn{2}{|c|}{ Evaluation criteria } \\
\hline & Std & 0.0698 \\
\hline & Pearson (r) & 0.998 \\
\hline & $\mathrm{R}^{2}$ & 0.996 \\
\hline
\end{tabular}

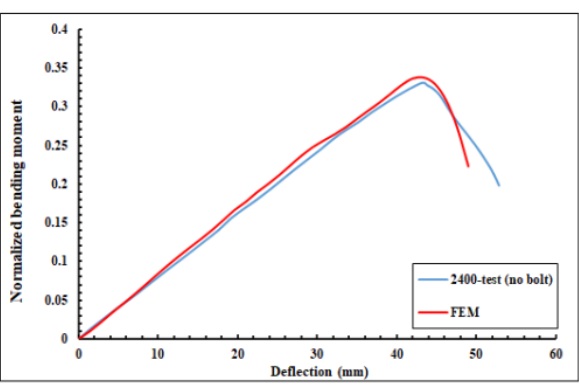

(a)

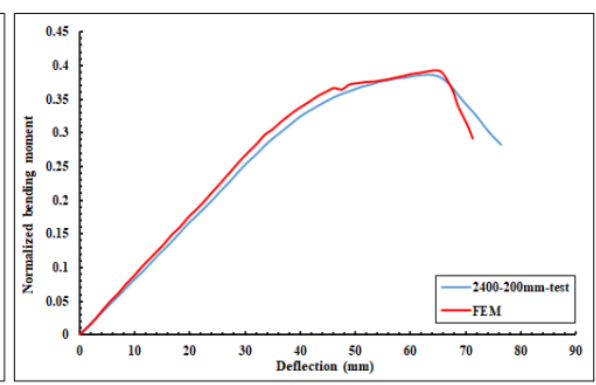

(b)

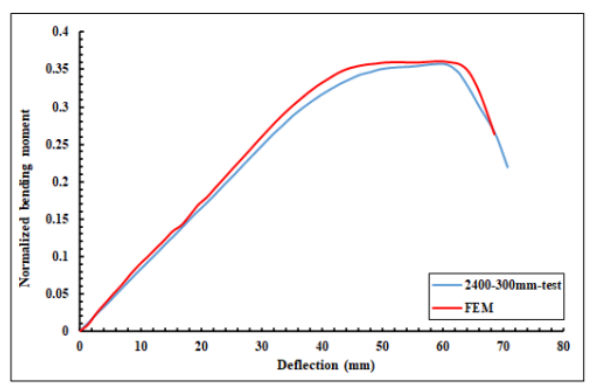

(c)

Figure 8. Comparison of FE model against major-axis test results for (a) non-reinforced model, (b) 200 mm reinforced model and (c) $300 \mathrm{~mm}$ reinforced model.

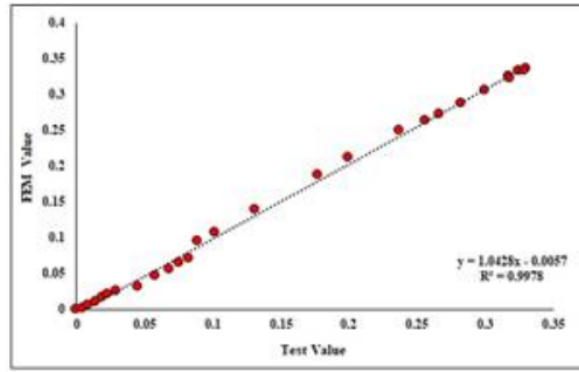

(a)

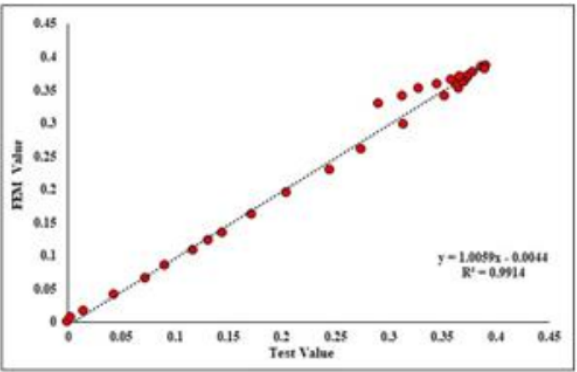

(b)

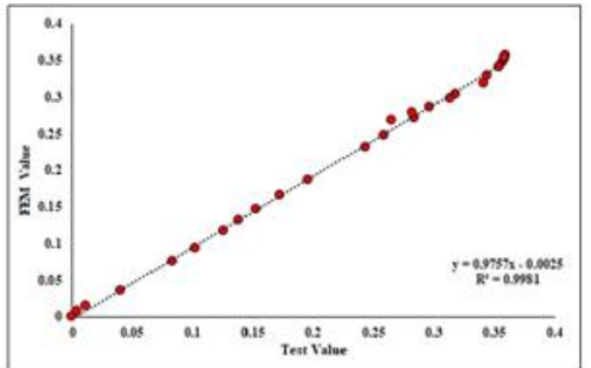

(c)

Figure 9. Linear regression diagram for; (a) non-reinforced model, (b) $200 \mathrm{~mm}$ reinforced model, and (c) $300 \mathrm{~mm}$ reinforced model.

\subsection{Parametric Finite Element Study}

As discussed in the previous section, the FE model is capable of simulating the actual testing condition with minimum error. Hence, in this section, the verified FE method is utilized for a parametric study to investigate various uprights with different heights and thicknesses as well as different reinforcement spacings under flexural loading. The models for the parametric study are presented in Table 1 . The results of the parametric study are classified into two groups of loading under major and minor axes, which are presented in the following sections. The convention used to name the specimens is shown in Figure 10. 
Table 4. FEM vs. experimental results accuracy details in terms of evaluation criteria.

\begin{tabular}{|c|c|c|}
\hline \multirow{4}{*}{ Non-reinforced model } & \multicolumn{2}{|c|}{ Evaluation criteria } \\
\hline & Std * & 0.1242 \\
\hline & Pearson (r) & 0.9989 \\
\hline & $R^{2}$ & 0.9978 \\
\hline \multirow{4}{*}{$200 \mathrm{~mm}$ reinforced model } & \multicolumn{2}{|c|}{ Evaluation criteria } \\
\hline & Std & 0.1357 \\
\hline & Pearson (r) & 0.9957 \\
\hline & $\mathrm{R}^{2}$ & 0.9914 \\
\hline \multirow{4}{*}{$300 \mathrm{~mm}$ reinforced model } & \multicolumn{2}{|c|}{ Evaluation criteria } \\
\hline & Std & 0.1224 \\
\hline & Pearson (r) & 0.999 \\
\hline & $\mathrm{R}^{2}$ & 0.9981 \\
\hline
\end{tabular}

*Std = standard deviation.

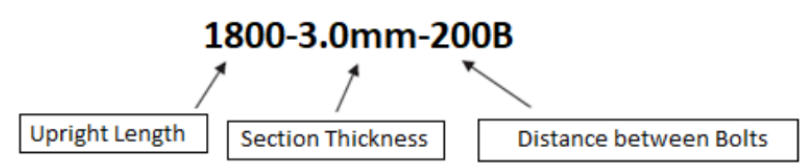

Figure 10. Designation of models.

\subsubsection{Parametric Study: Results of Major Axis}

The influence of various reinforcement spacings for the uprights under major axis loading has been discussed in this section. The normalized moment-displacement curves of the numerical models for each thickness are indicated in Figures 11-14. As it is observed from the figures, using more reinforcement to partially close the section leads to improving the specimen's flexural capacity.
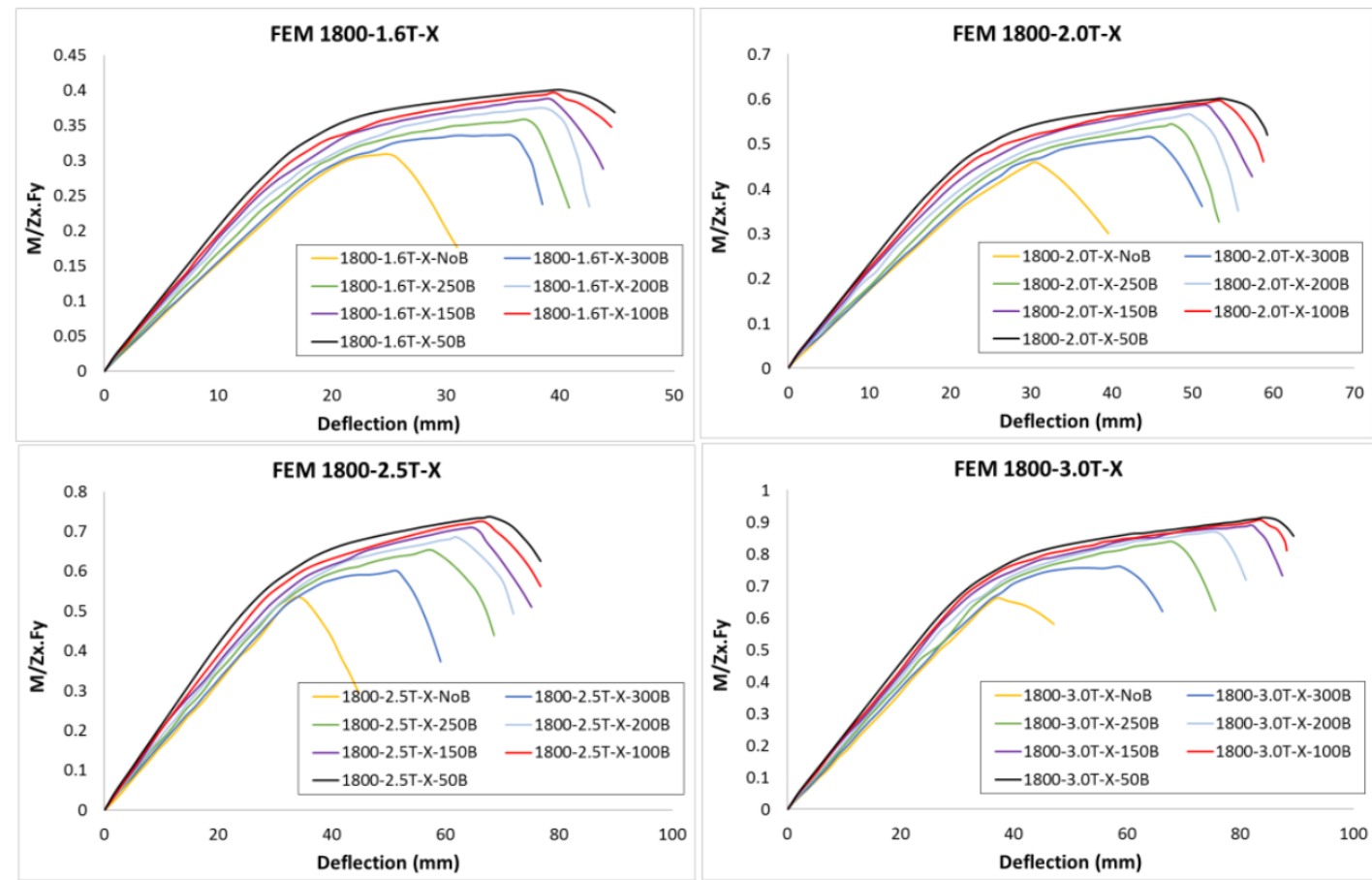

Figure 11. Normalized moment-deflection curves for $1800 \mathrm{~mm}$ models about major axis. 

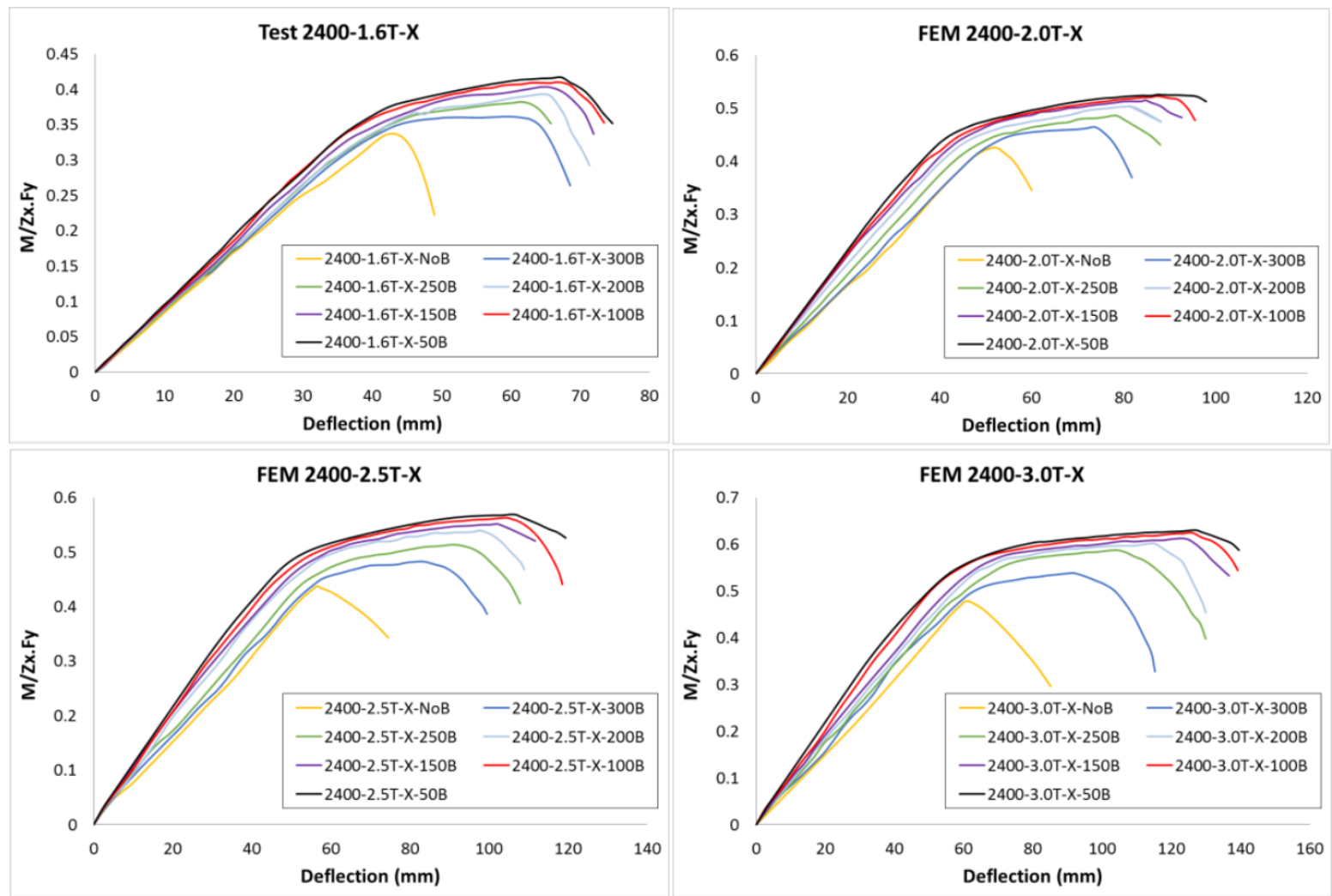

Figure 12. Normalized moment-deflection curves for $2400 \mathrm{~mm}$ models about major axis.
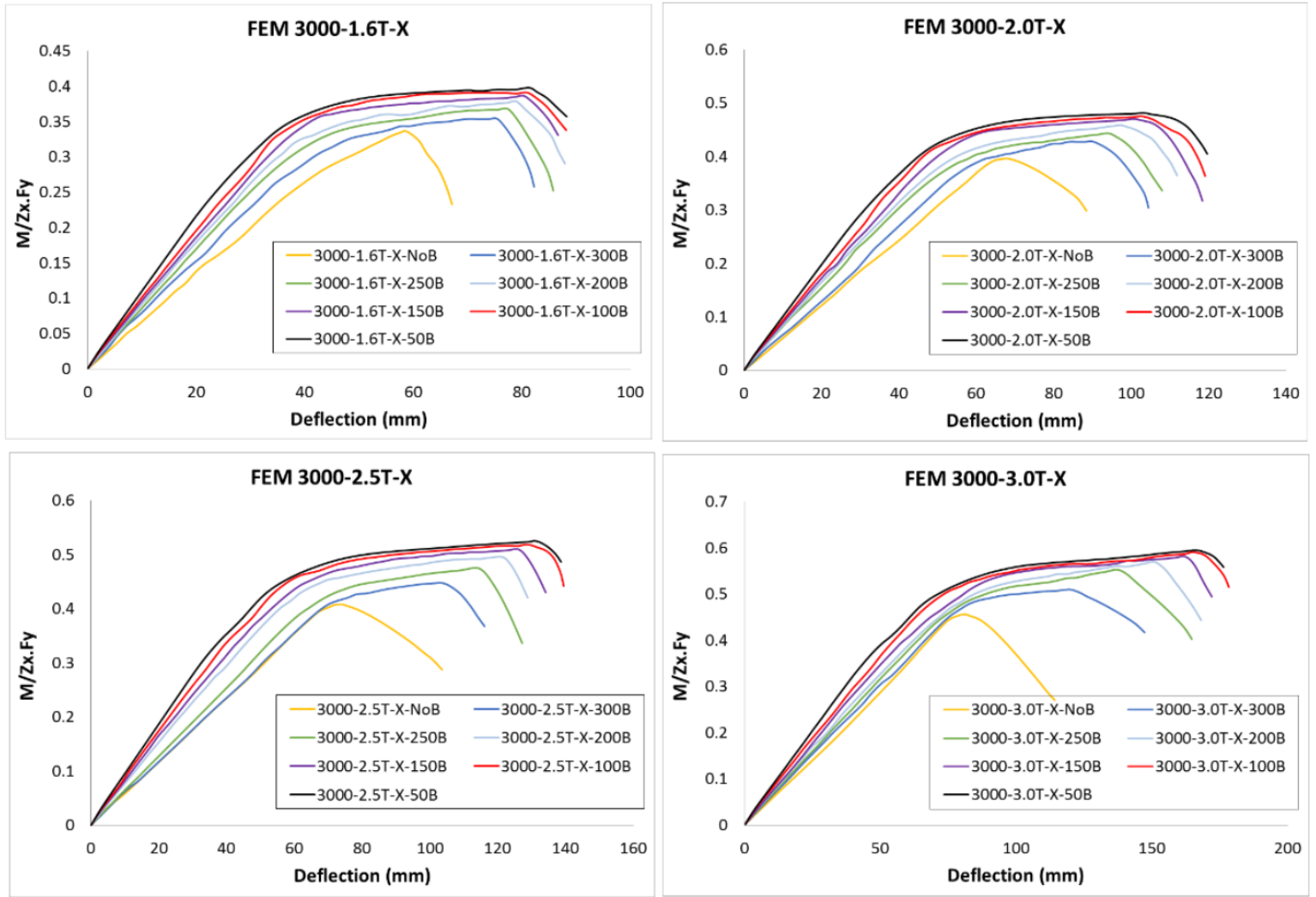

Figure 13. Normalized moment-deflection curves for $3000 \mathrm{~mm}$ models about major axis. 

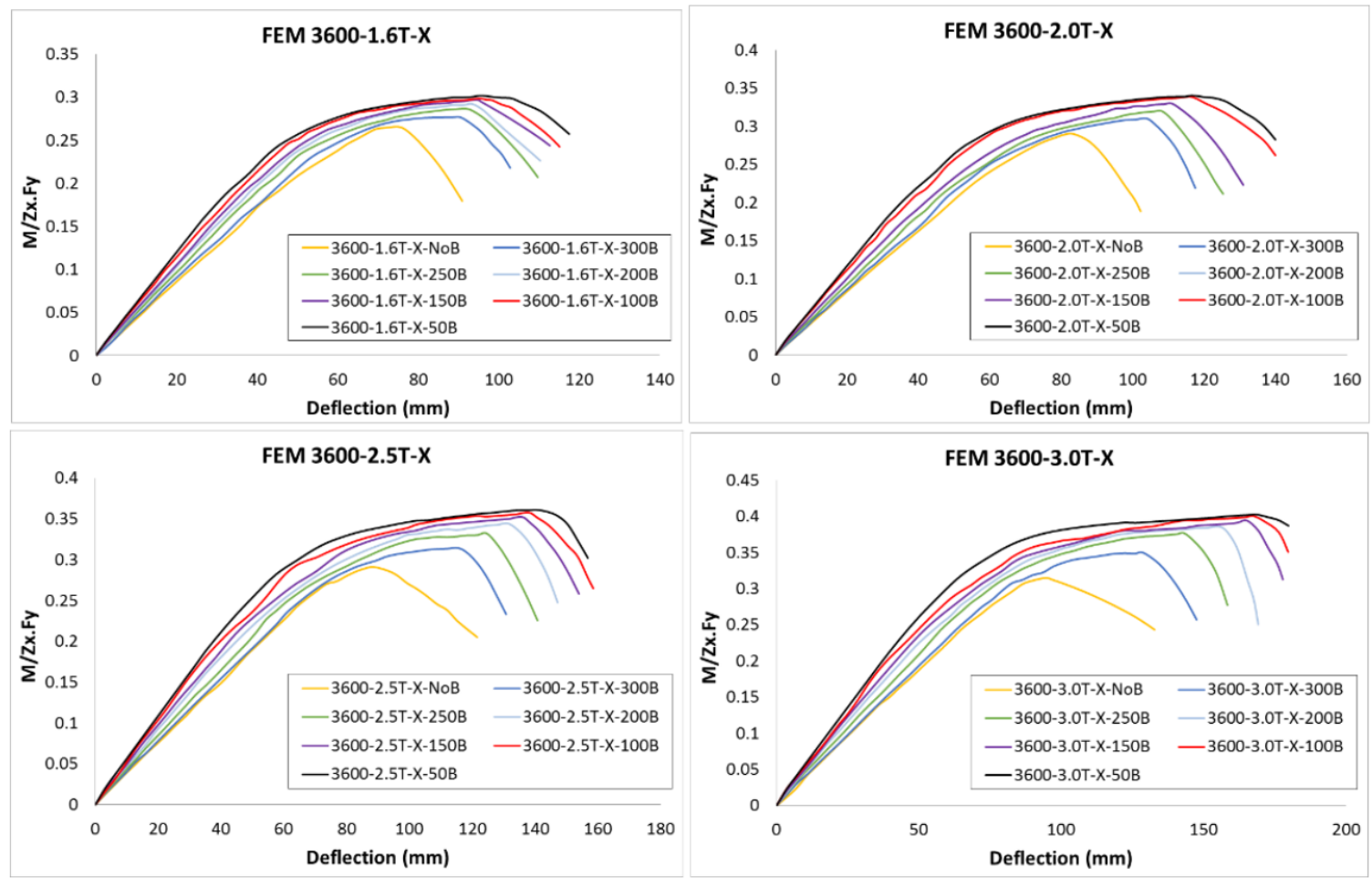

Figure 14. Normalized moment-deflection curves for $3600 \mathrm{~mm}$ models about major axis.

Figure 15 displays the normalized ultimate moment of the sections with various thicknesses at different reinforcement spacings. It is deduced that the shorter reinforcement spacing increases the ultimate bending capacity of the sections.
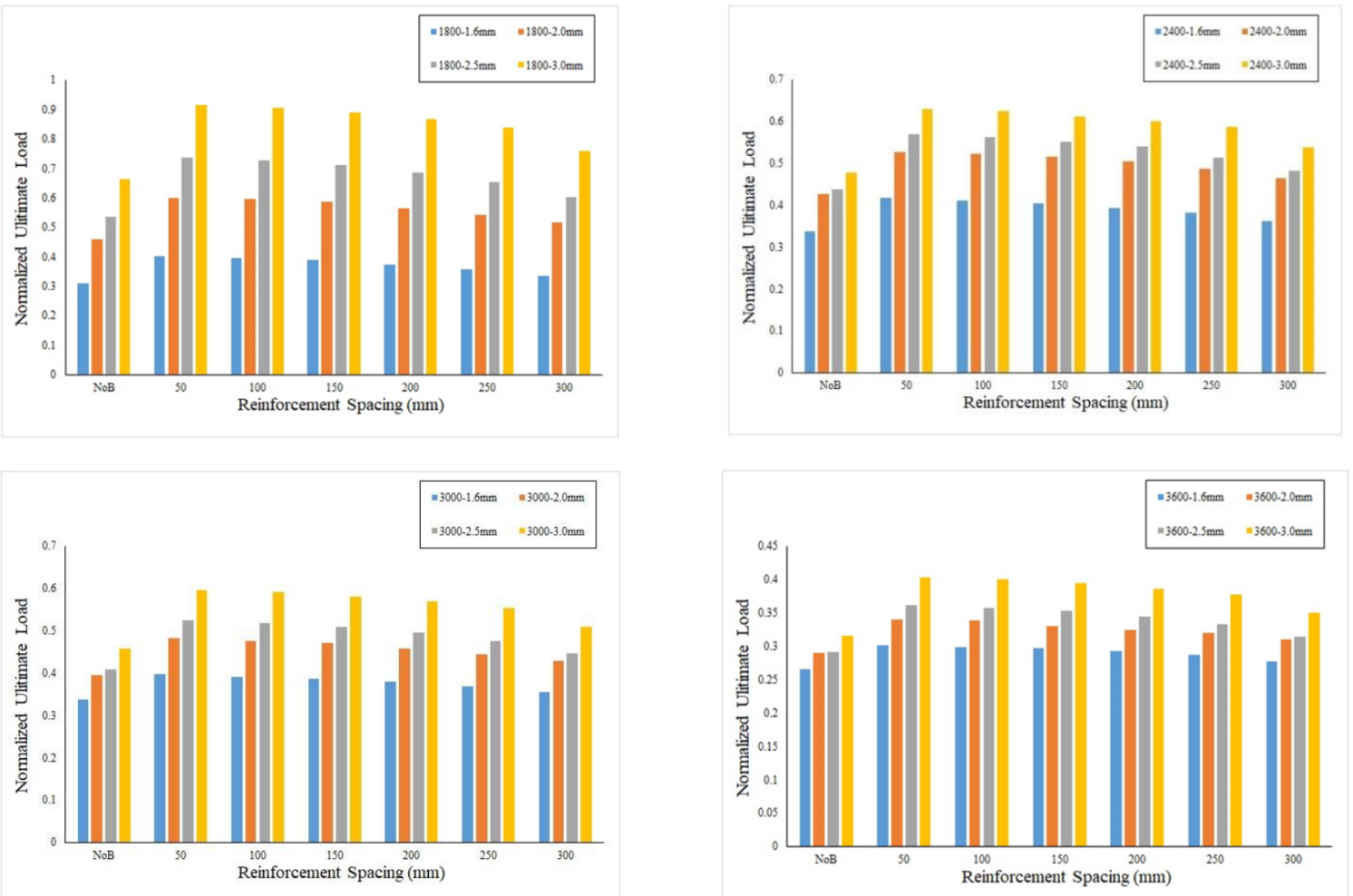

Figure 15. The normalized ultimate moment of 1800, 2400, 3000, and $3600 \mathrm{~mm}$ models about major axis with respect to reinforcement spacing. 
The increased ultimate moment percentage utilizing various reinforcement spacing for the profiles from $1800 \mathrm{~mm}$ to $3600 \mathrm{~mm}$ length with respect to specimens without reinforcement is presented in Figure 16. In general, the reinforcement technique influences the ultimate capacity of the open sections in a range of about $5 \%$ to $40 \%$. As it is seen, reinforcement addition from $300 \mathrm{~mm}$ spacing to $50 \mathrm{~mm}$ spacing can improve the frame's strength by a significant amount. It is also found that reducing reinforcement spacing (up to $50 \mathrm{~mm}$ ) can considerably increase the ultimate strength of the upright section under flexural loading.
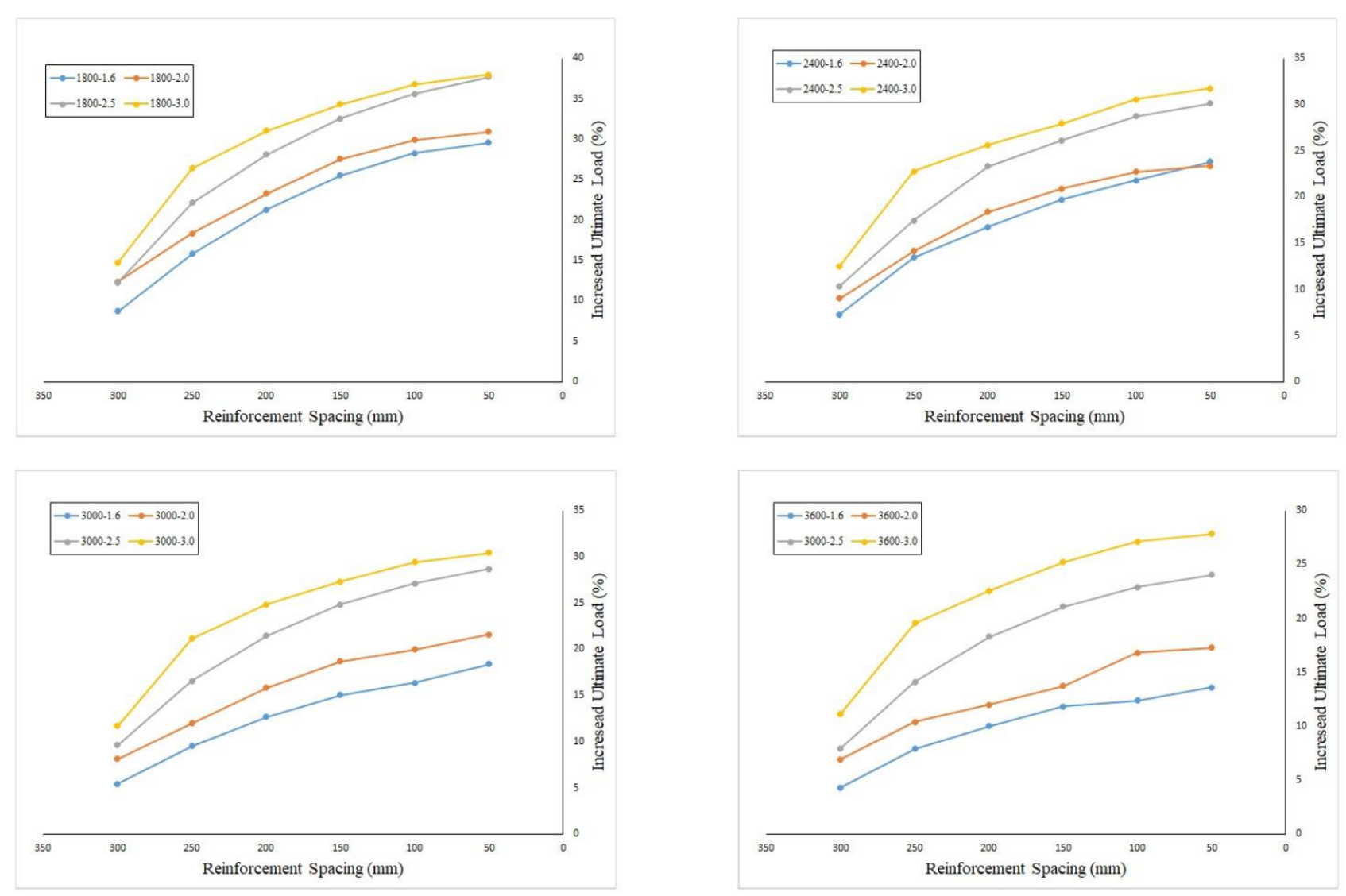

Figure 16. Percentage of increased ultimate load of major axis analysis with different reinforcement spacing in length order.

\subsubsection{Parametric Study: Results of Minor Axis}

The effect of different reinforcement spacings for the uprights under minor axis loading is discussed in this section. Minor axis models are provided with the same spacing and the same thickness as the major axis models. Figures 17-20 indicate the normalized load-displacement curves for different models and thicknesses under minor axis loading. According to the figures, thickness and length play important roles in flexural strength. Additionally, more reinforcement leads to more ultimate strength. Figures 17-20 show that using reinforcement with shorter spacing increases the strength of the sections. Sections with a shorter length and thicker cross-sections already have higher flexural strength, but this strength is improved noticeably by employing reinforcement. Due to the restrained buckling and better distribution of force along the section's length, specimens with dense reinforcements indicate better distortional buckling behavior. Generally, the distortional buckling behavior is enhanced, and section failure is changed from general global buckling to local buckling, mostly due to partial closing of the upright section. 

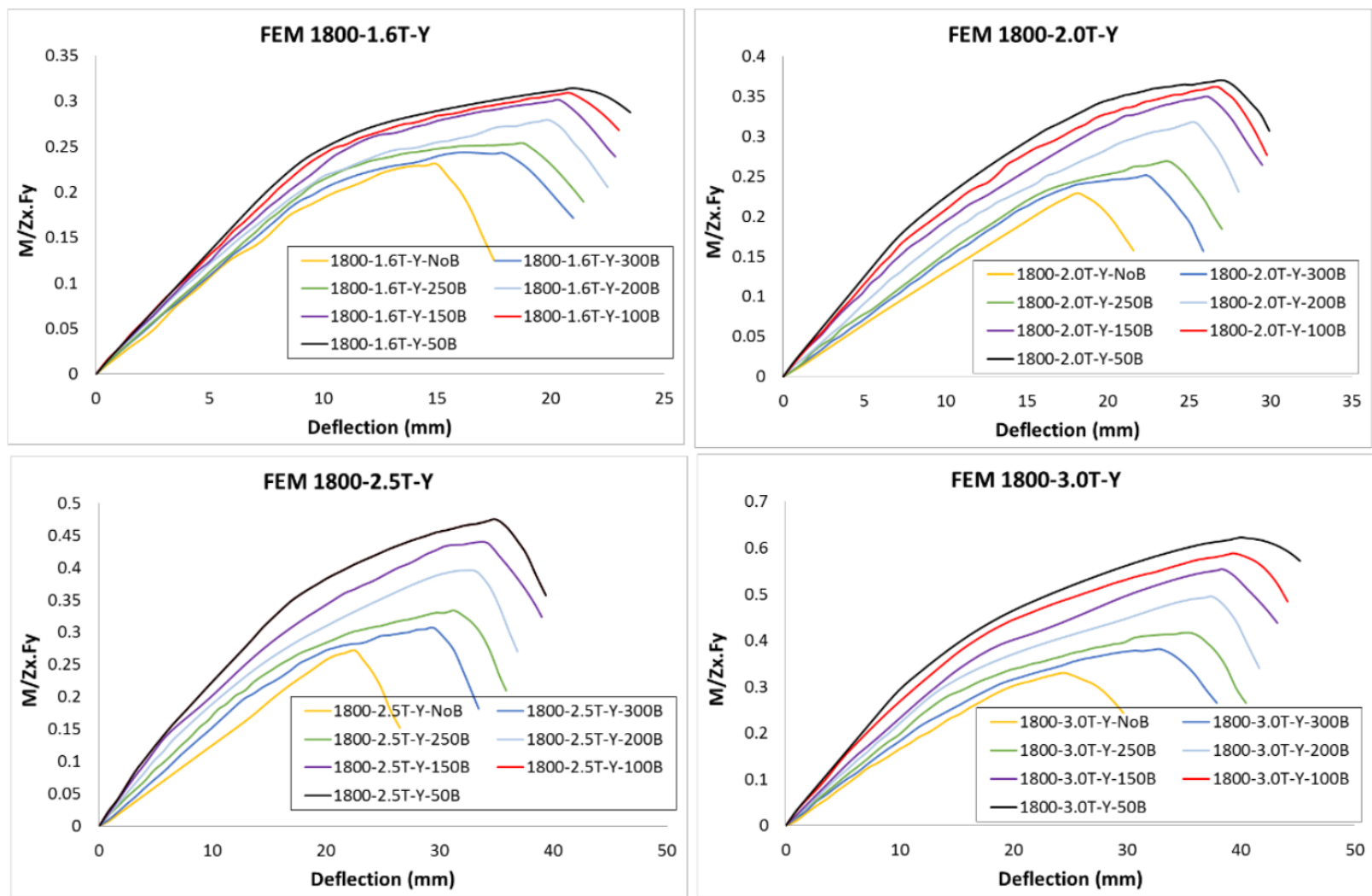

Figure 17. Normalized moment-deflection curves for $1800 \mathrm{~mm}$ models about minor axis.
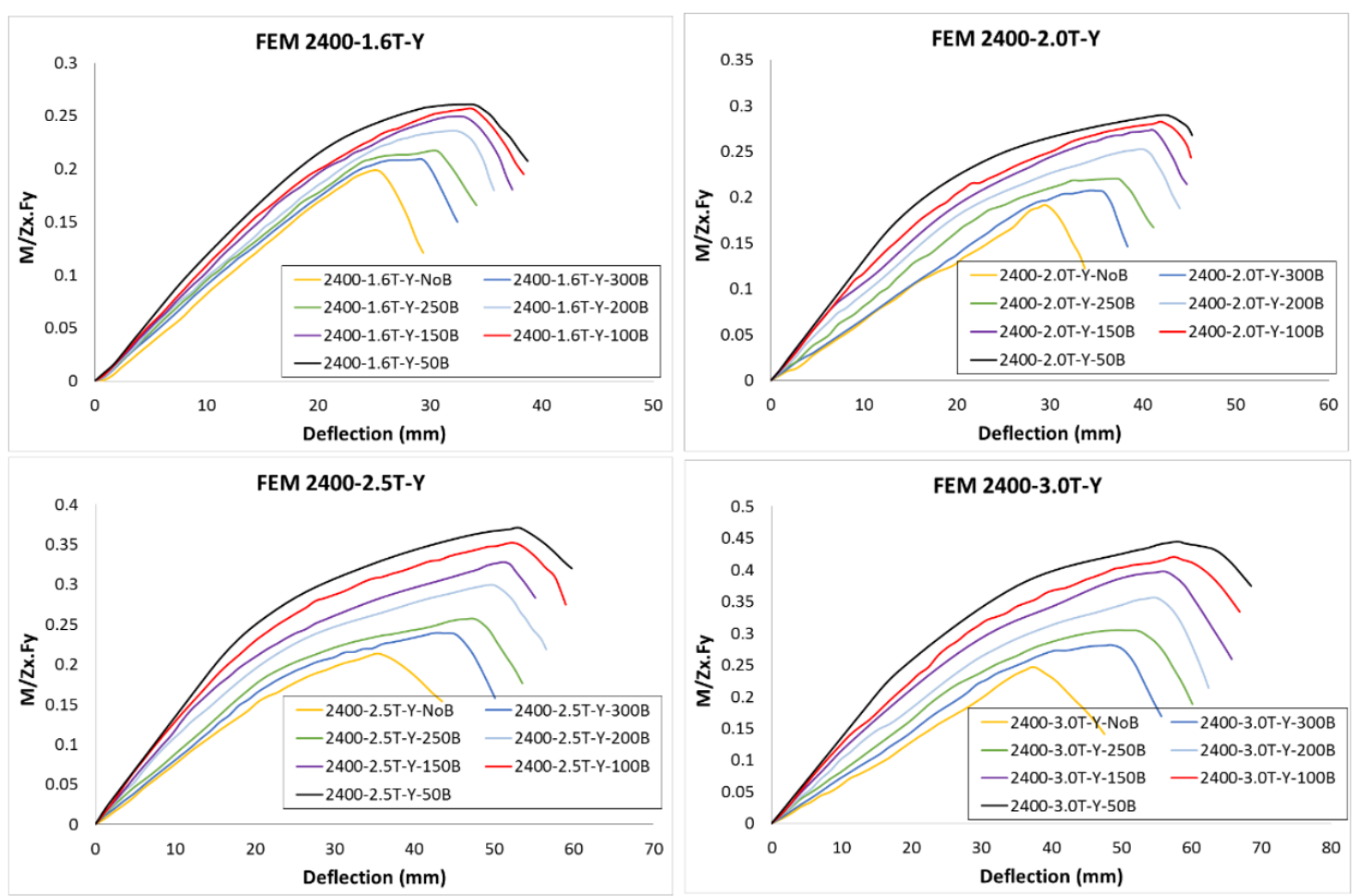

Figure 18. Normalized moment-deflection curves for $2400 \mathrm{~mm}$ models about minor axis. 

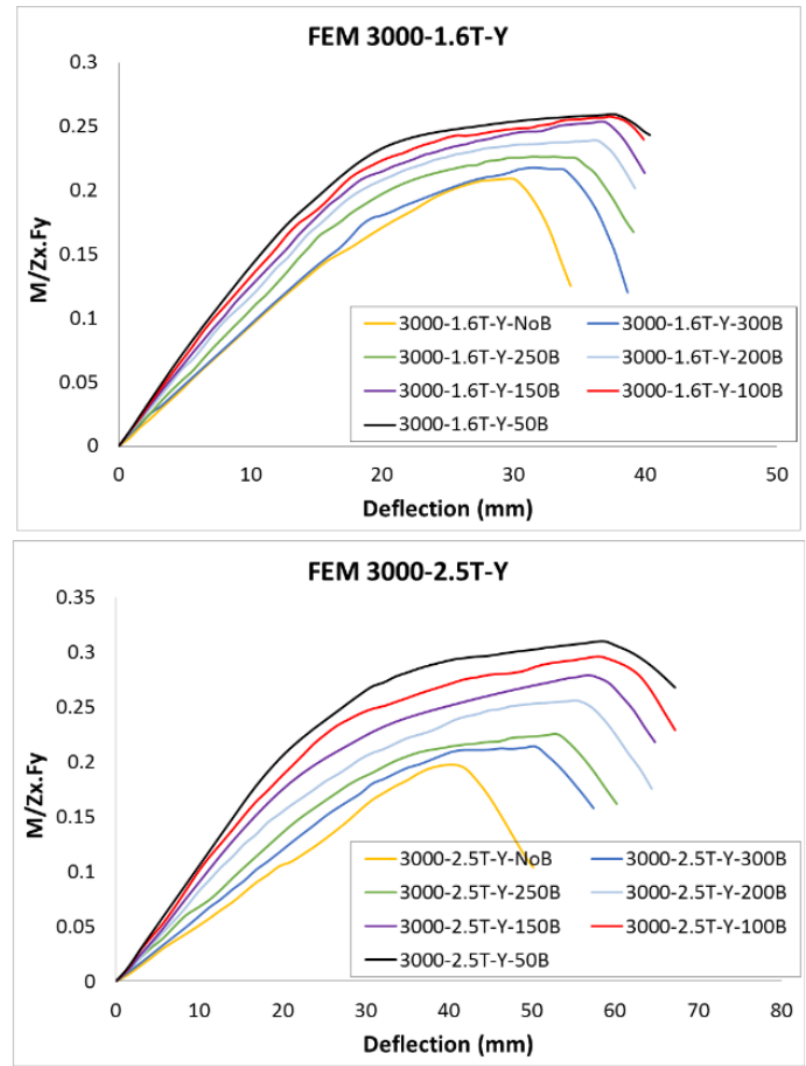
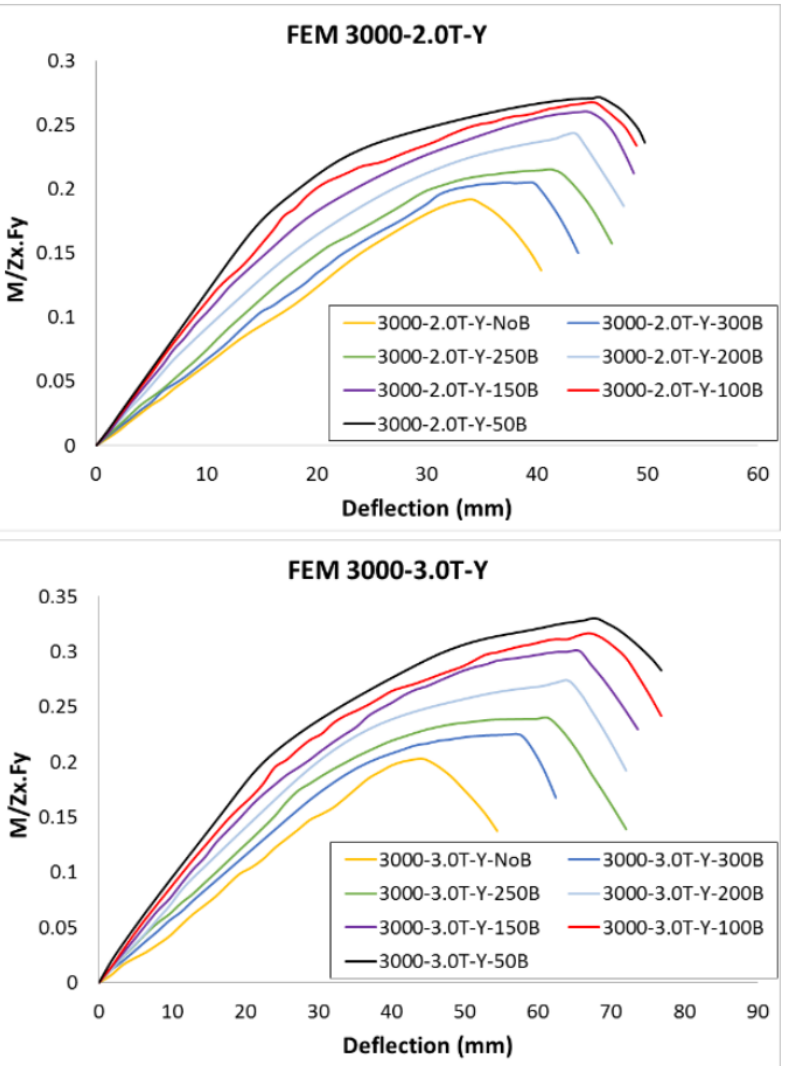

Figure 19. Normalized moment-deflection curves for $3000 \mathrm{~mm}$ models about minor axis.
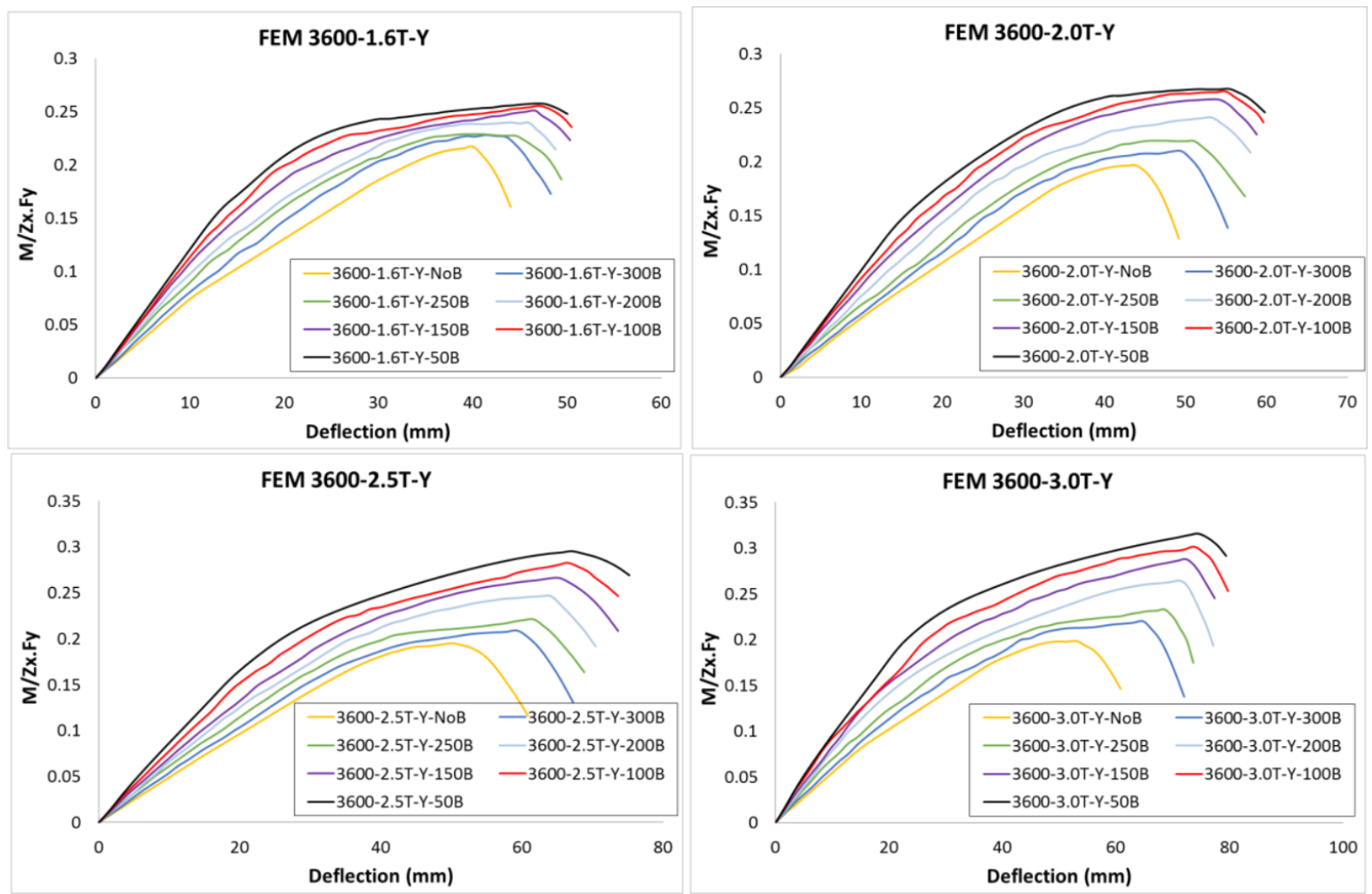

Figure 20. Normalized moment-deflection curves for $3600 \mathrm{~mm}$ models about minor axis. 
Figure 21 indicates the normalized ultimate flexural strength with respect to the reinforcement spacing for models under minor axis loading. It can be observed that length has an inverse relation with flexural strength, where both spacing and thickness have a direct relation with the ultimate load. Hence, shorter models with higher thickness and shorter reinforcement spacing indicate higher flexural strength. For example, the model with $1800 \mathrm{~mm}$ length and $3 \mathrm{~mm}$ thickness (1800-3.0 mm) with $50 \mathrm{~mm}$ reinforcement spacing shows the greatest ultimate load.
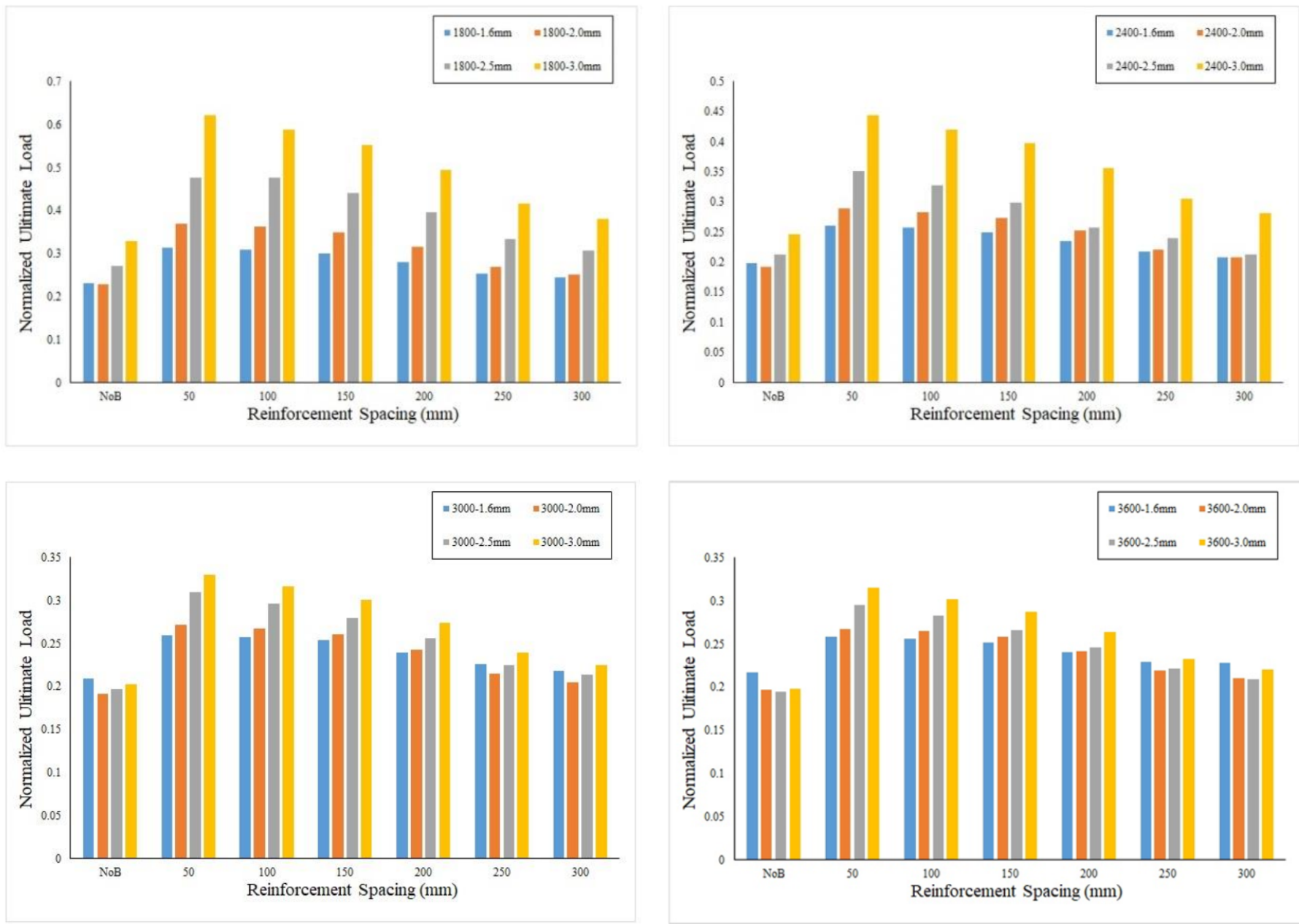

Figure 21. The normalized ultimate moment of 1800, 2400, 3000, $3600 \mathrm{~mm}$ models about minor axis with respect to reinforcement spacing.

Figure 22 illustrates a comparison between different increased ultimate loads with respect to reinforcement spacing with length order. Spacing and thickness have the same contribution in increasing the flexural strength. 

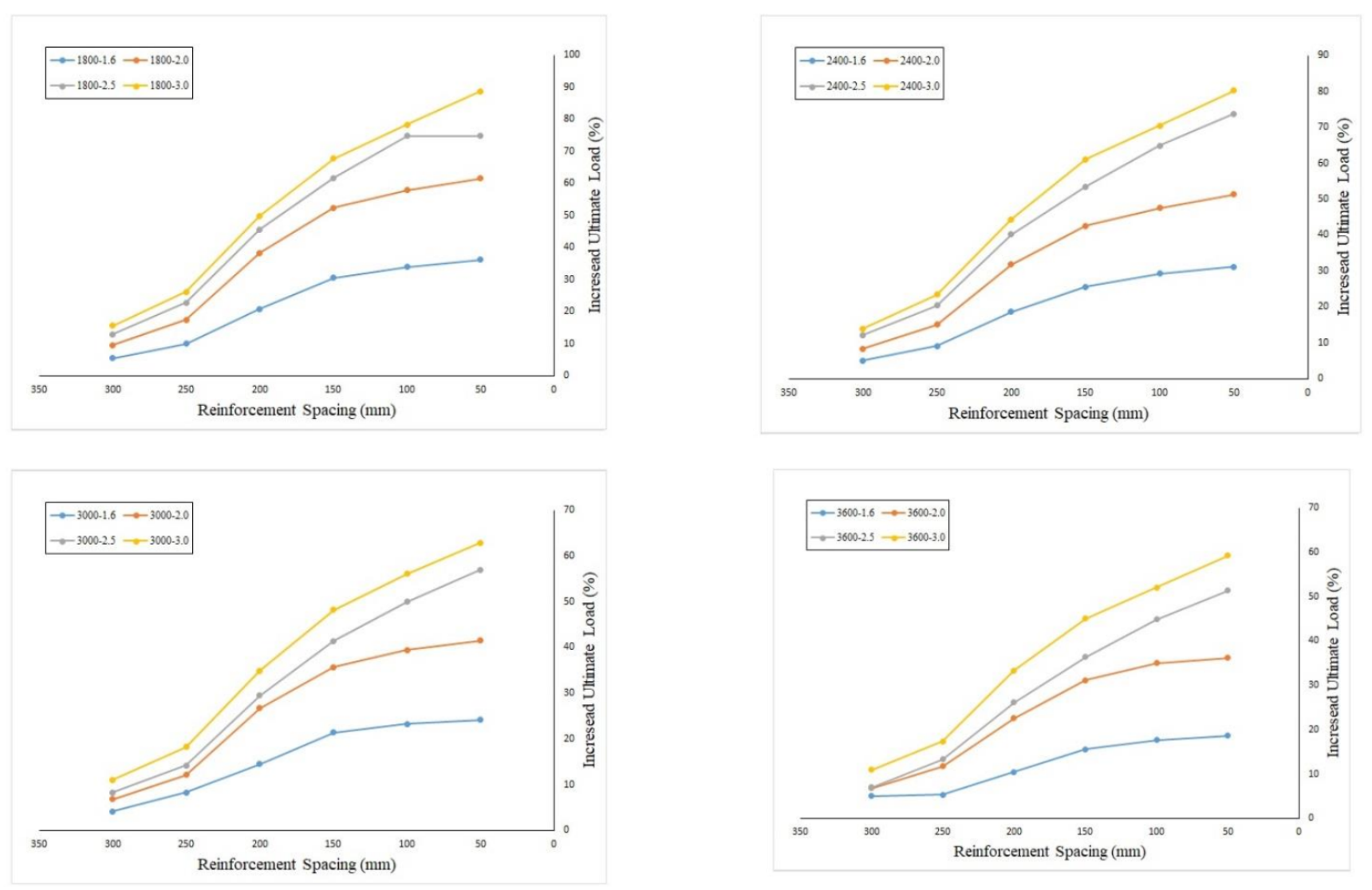

Figure 22. Percentage of increased ultimate load with different reinforcement.

\section{Artificial Intelligence Prediction}

Neural network systems are proved as highly valued approaches for data prediction regarding the different numerical research studies $[17,20,26]$. The strategy for using a specific type of network depends on different factors, including data behavior (linear, nonlinear), number of inputs, number of outputs and the research innovation $[15,27,28]$. The process of developing the network relies on trial and error identification, which the basis algorithm and possible supplementary methods detect $[29,30]$. The combination of the multi-layer perceptron (MLP) neural network with the particle swarm optimization (PSO) algorithm, which is based on the random production of the initial population, is employed in this study. In order to identify the most effective input for this hybrid neural network, instead of traditional methods and manually testing possible scenarios, the feature selection technique, which is the best way to identify the features of an issue, is employed in this paper. The main point of this study is to use the feature selection technique to identify the most effective parameter on the flexural capacity of the CFS uprights to predict and identify the deflection and ultimate flexural load simultaneously.

\subsection{Algorithm Methodology}

\subsubsection{Multi-Layer Perceptron (MLP) Algorithm}

MLP networks can be used as powerful hyper-surface reconstruction tools, which can successfully map a set of multi-dimensional input data $\left(\mathrm{x}_{\mathrm{i}} ; \mathrm{i}=1, \ldots, \mathrm{N}\right)$ onto a set of appropriate multidimensional outputs $\left(\mathrm{y}_{\mathrm{i}} ; \mathrm{i}=1, \ldots, \mathrm{N}\right)$. The MLP configuration is extensively used for static regression applications and it consists of one input layer, one or more hidden layer(s) and one output layer. The MLP network utilizes a supervised learning technique called backpropagation for training the network. The basic element of the modified un-stabilized MLP neural network is shown in Figure 23, which performs a projection oriented mathematical operation on its inputs. 


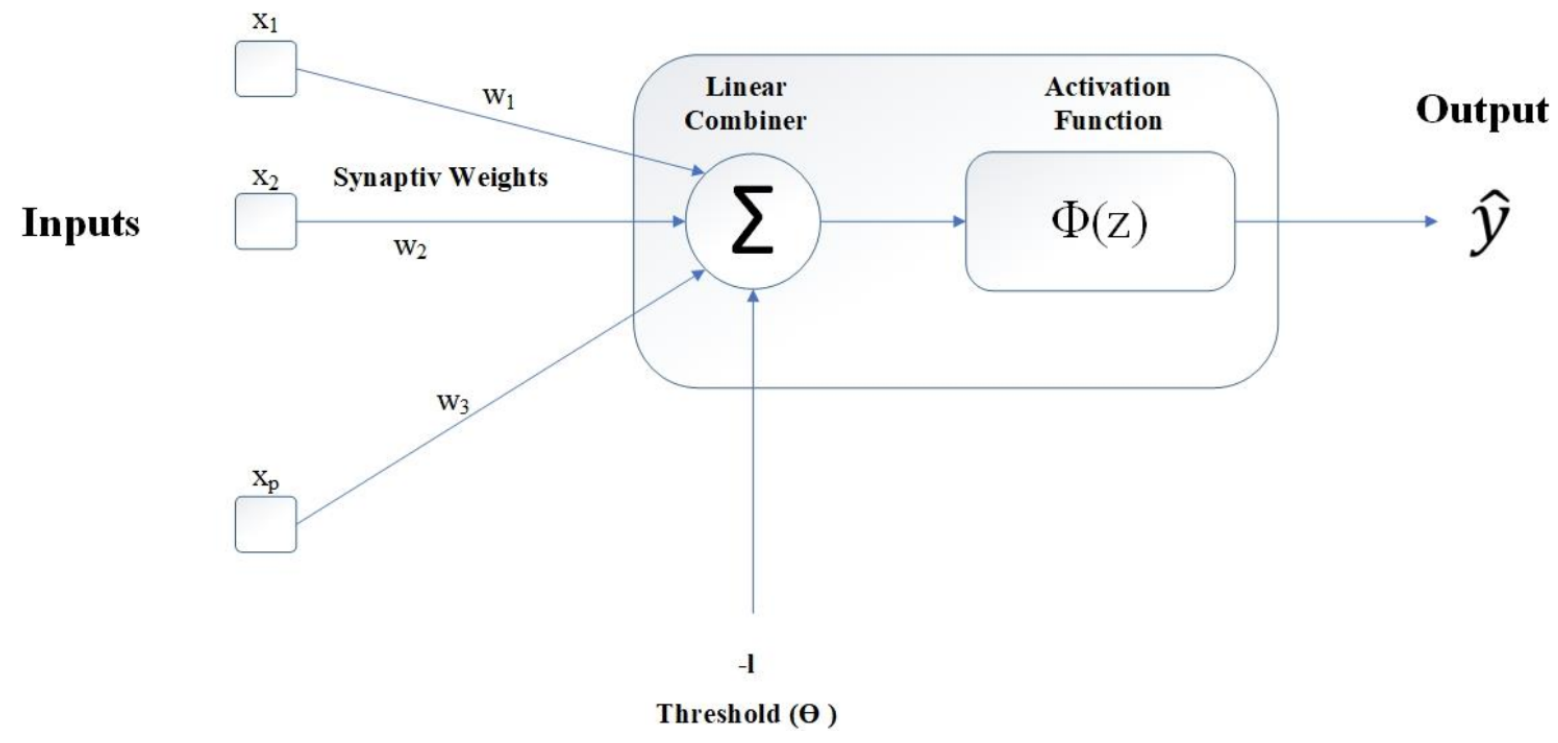

Figure 23. Schematic representation of MLP neuron.

Non-linear activation function $(\varphi)$ performs a pre-defined mathematical operation over its argument and provides the model predictions $(y(x))$. Sigmoid, hyperbolic tangent, threshold and piecewise-linear basis functions are the most popular activation functions traditionally used for MLP networks. The MLP network is developed by assigning the synaptic weights deriving from a PSO algorithm in this study. As shown in Figure 24, additional linear weights $\left(\alpha_{1}, \ldots, \alpha_{M}\right)$ are used in our modified MLP network.

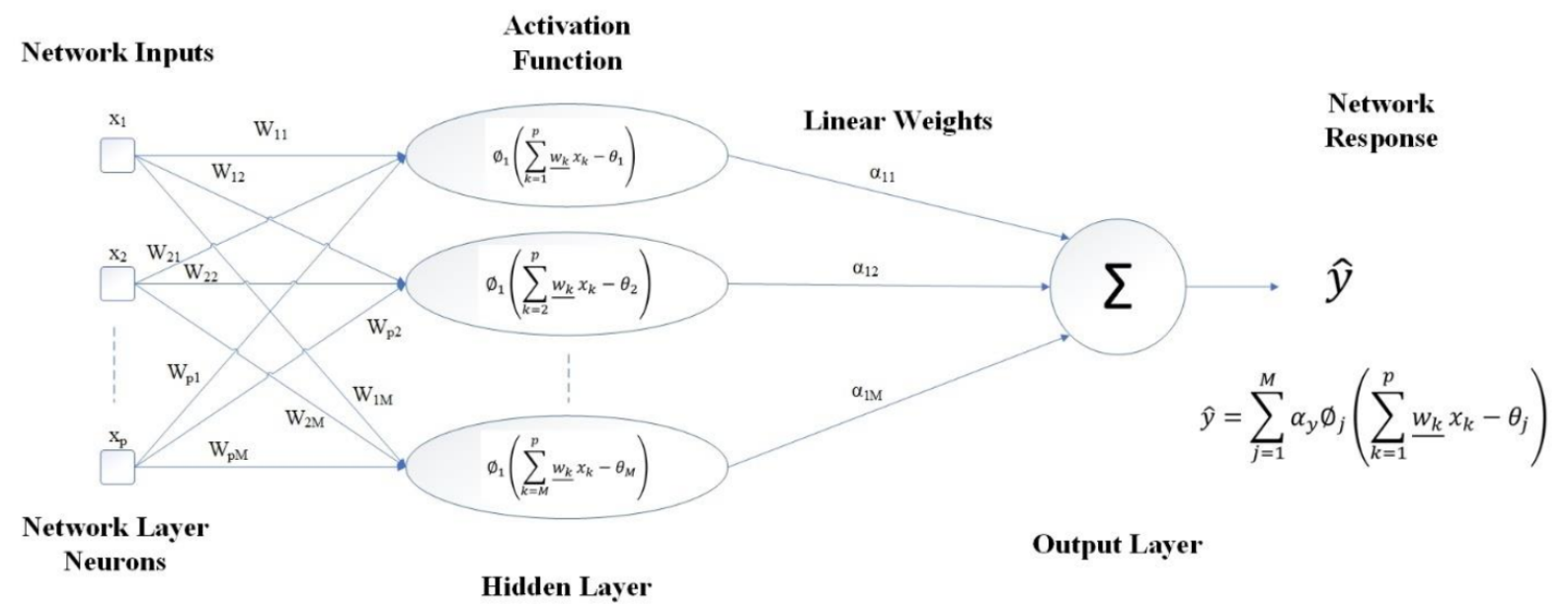

Figure 24. Visualization of a single hidden layer MLP network.

In the present study, the MLP algorithm was developed and trained by several bending test data obtained from the experimental tests [9] as well as the FEM results discussed in the previous sections.

\subsubsection{Particle Swarm Optimization (PSO)}

PSO is a powerful algorithm for optimization in nonlinear, non-convex and discontinuous environments. This algorithm is very powerful and efficient while defining many parameters. In this algorithm, particles are the building blocks of the population, and with the intelligence that they have, a certain amount of intelligence is created that is not comparable to the intelligence of each of them. Figure 25 indicates the PSO sequential flowchart. 


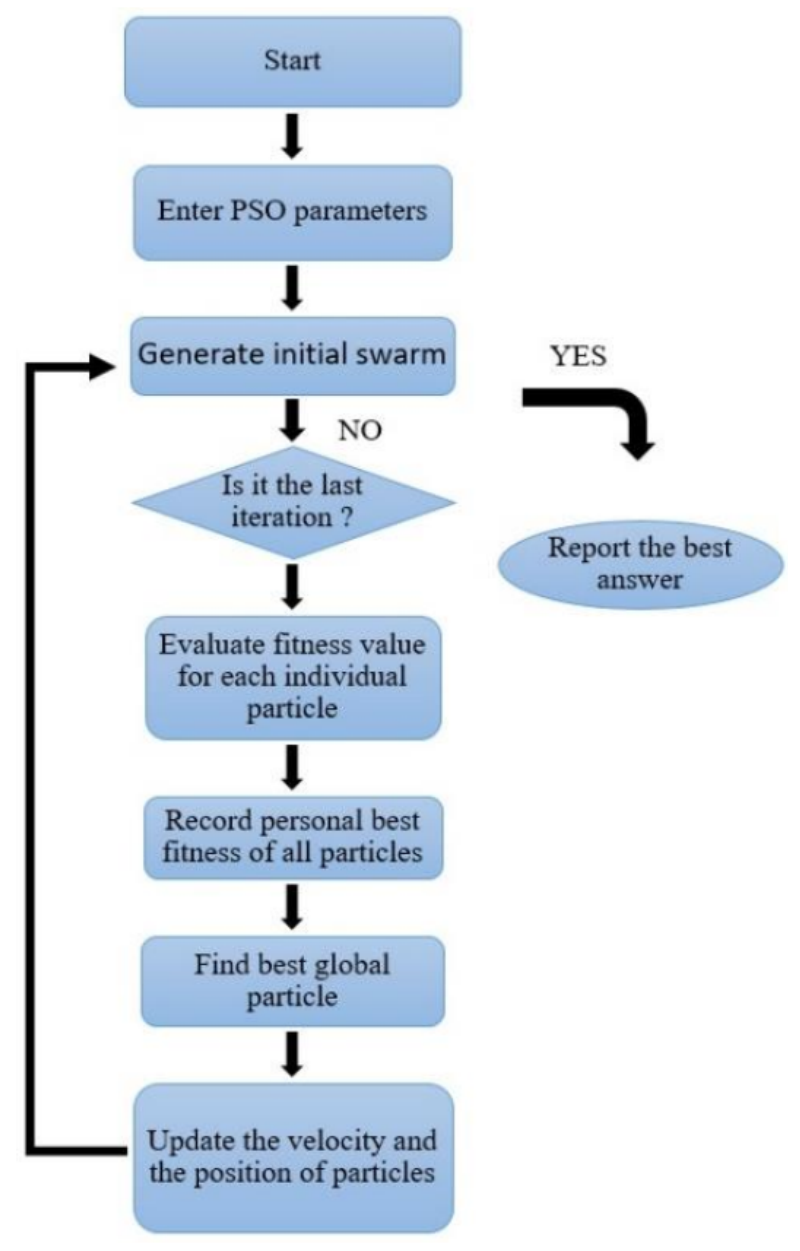

Figure 25. PSO sequential flowchart.

In this study, the PSO algorithm is employed along with MLP as a unique intelligence algorithm. The goal of the PSO algorithm is to find the optimal objective function.

\subsubsection{Feature Selection Technique (FS)}

"Feature selection" is a process of selecting a subcategory from a category of features [31]. It is preferable in contexts where readability and interpretability are issues of concern because the discounted values of the main features are preserved in the reduced space. This method of dimension reduction results in a qualitative database, without the removal of useful information. It also allows for features with different data models to be combined. The issue is of importance because a large number of features are often used in different applications. Therefore, the need to select a limited set among them becomes apparent. The feature selection process is divided into four parts as shown in Figure 26: generation procedure, evaluation function, stopping criteria and validation procedure.

In this study, some prominent features of CFS racking uprights are produced through one or more conversions on input features. While mapping points from one space with higher dimensions into another space with lower dimensions, a large number of points may overlap. Feature extraction helps to find a new dimension where a minimum number of points overlap. This approach is associated with the problem area and is commonly used in image processing where specific features are extracted in accordance with the requirements of the problem. 


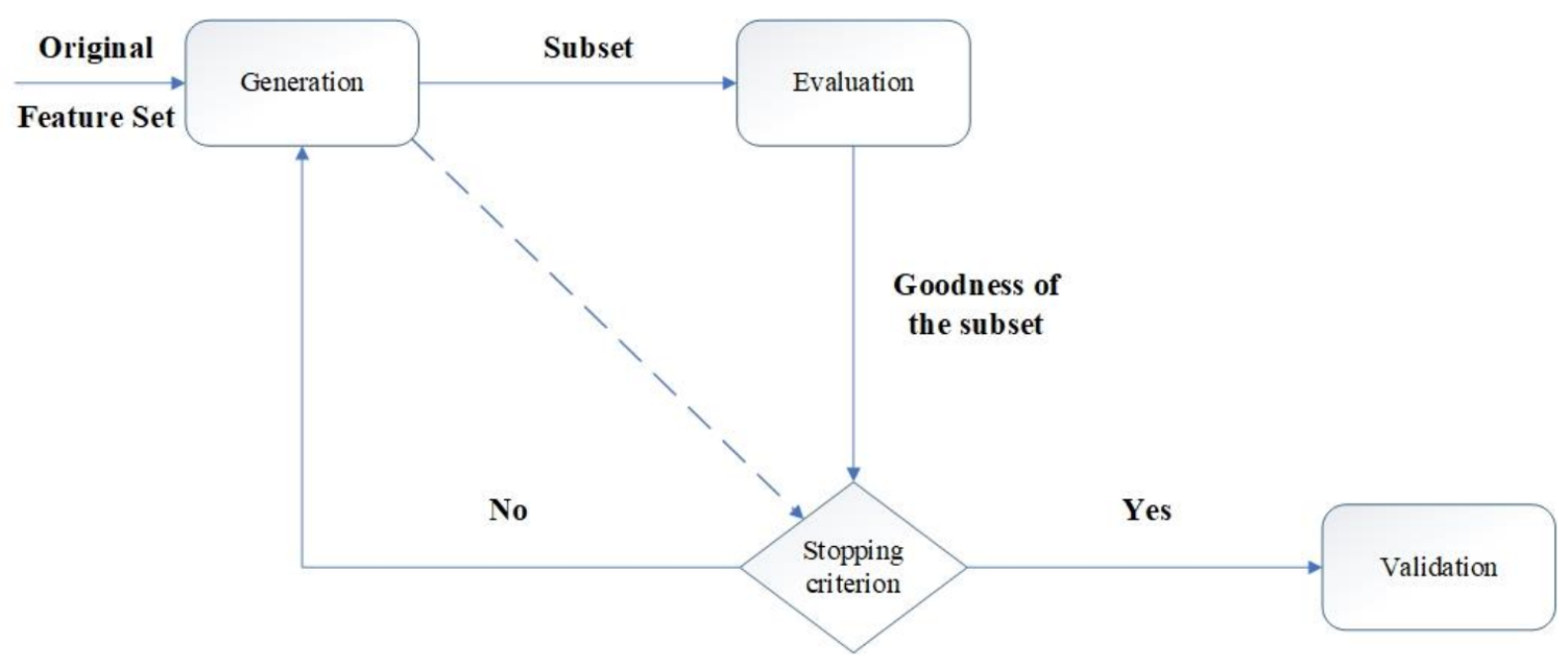

Figure 26. Feature selection technique steps.

\subsubsection{MLP-PSO-FS Architecture}

The way that the algorithm works is that the MLP neural network starts learning based on the initial configuration. For data with relatively high complexity, learning a simple neural network without an optimizer may not be enough, hence using an optimizer technique is required. PSO is one of these techniques that is based on the collective movement of birds and fish. The optimizer runs at a higher level than the neural network, meaning that each MLP neural network calculation itself is one of the PSO optimizer particles. If the feature selection technique is needed to find the best combination, this technique must be performed before executing the MLP-PSO set. In this way, first, FS obtains all possible states from the combination of inputs and then sends the first state to the hybrid neural network. After obtaining the final result, FS sends the second state to the neural network and the results are compared with each other. The best result is maintained and repeated for the third case. This is done until all scenarios are completed, and finally, the best input combination is identified. Figure 27 presents the diagram of the sequential PSO-FS and MLP combination.

\subsection{Performance Evaluation}

In this paper, several performance measures are employed to assess the proposed models. The R, NSE, RMSE, MAE and WI [32-36] are employed as the measure of precision in this study, which is represented as follows:

$$
\begin{gathered}
R=\frac{\sum_{i=1}^{M}\left(O_{i}-\overline{O_{l}}\right) \cdot\left(P_{i}-\overline{P_{l}}\right)}{\sqrt{\sum_{i=1}^{M}\left(O_{i}-\overline{O_{l}}\right)^{2} \sum_{i=1}^{M}\left(P_{i}-\overline{P_{l}}\right)^{2}}} \\
N S E=1-\frac{\sum_{i=1}^{N}\left(P_{i}-O_{i}\right)^{2}}{\sum_{i=1}^{N}\left(O_{i}-\overline{O_{l}}\right)^{2}} \\
R M S E=\sqrt{\frac{1}{N} \sum_{i=1}^{N}\left(P_{i}-O_{i}\right)^{2}} \\
\text { MAE }=\frac{\sum_{i=1}^{M}\left|P_{i}-O_{i}\right|}{N} \\
\text { WI } 1-\frac{\sum_{i=1}^{N}\left(O_{i}-P_{i}\right)^{2}}{\sum_{i=1}^{N}\left(\left|P_{i}-\overline{O_{l}}\right|+\left|O_{i}-\overline{O_{l}}\right|\right)^{2}}
\end{gathered}
$$


where $O_{i}$ and $P_{i}$ are the observed and predicted values, respectively; $\overline{O_{i}}$ and $\overline{P_{i}}$ indicate the average of the observed and predicted values, respectively, and the number of data is shown by $\mathrm{N}$. The $\mathrm{R}$ index [Range $=(0-1)$; ideal value $=1$ ] shows the suitability of the selected predictors applied for the prediction of the target variable. NSE [Range $=(-\infty, 1)$; ideal value $=1$ ] is demonstrated to evaluate the capability of the suggested methods. The highest value of unity reveals an appropriate fit between the actual and measured value for which a negative value shows that the performance of the model is worse than the arithmetic mean of the developed models. The RMSE and MAE [Range $=(0,+\infty)$; ideal value $=0$ ] are measures for assessing the accuracy, which are greater or equal to zero in value. WI $[$ Range $=(0,1)$; ideal value $=1]$ is a standardized indicator for model prediction error. The values close to 0 demonstrate poor precision, while the values close to unity reveal the goodness of prediction.

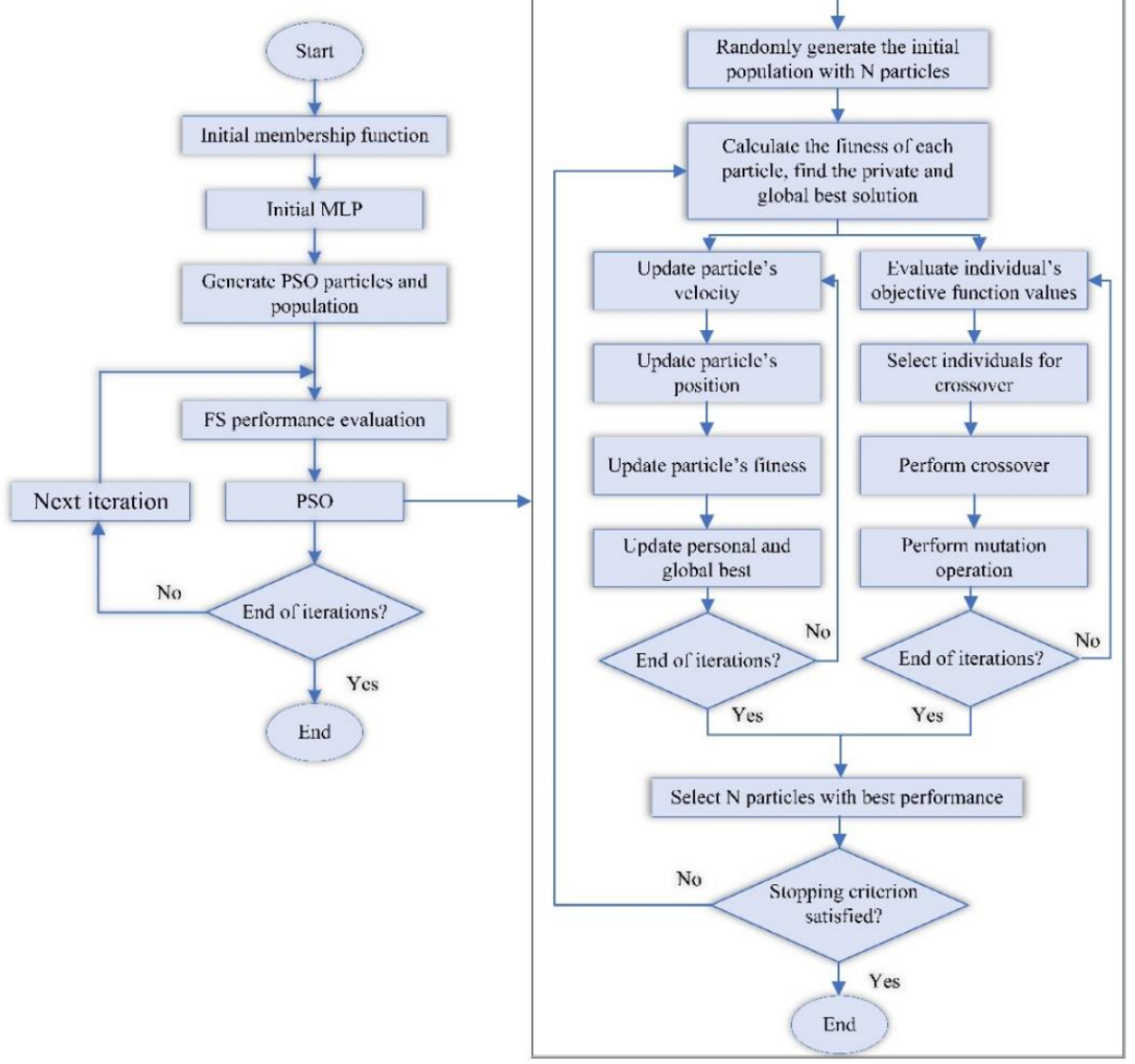

Figure 27. Flowchart of the sequential combination of hybrid MLP-PSO-FS algorithm.

\subsection{Algorithm Results and Discussion}

The dataset used in this research is the result of several experiments that ultimately formed 5111 rows of information. This database has six inputs and one target output. In this investigation, choosing the combination of the influential input for the prediction matrix of the load MLP, which is tuned by PSO, is carried out as the main neural network model. The variables affecting load are indicated in the functional relationship as follows:

$$
\text { Load }=f(\text { length, bolts, thickness, M/ZY.Fy, Ult Moment, Ult Load })
$$

MLPs are useful in research due to their ability to address the problems stochastically, which often allows approximate solutions for extremely complicated problems, such as fitness approximation. In this part, according to the training datasets, MLP is fitted. 
Therefore, MATLAB software is utilized to predict the load by the use of hybrid PSO with MLP. The best result is given in Tables 5 and 6.

Table 5. Best achieved results in deflection estimation.

\begin{tabular}{cccccc}
\hline \multirow{2}{*}{ Phase } & \multicolumn{5}{c}{ Network Result } \\
\cline { 2 - 6 } & $\mathbf{R}$ & NSE & RMSE & MAE & WI \\
\hline Test & 0.948 & 0.886 & 5.415 & 3.235 & 0.972 \\
\hline Train & 0.943 & 0.878 & 5.702 & 3.303 & 0.970 \\
\hline
\end{tabular}

Table 6. Best achieved results in normalized load estimation.

\begin{tabular}{ccccccc}
\hline \multirow{2}{*}{ Phase } & \multicolumn{7}{c}{ Network Result } \\
\cline { 2 - 7 } & $\mathbf{R}$ & NSE & RMSE & MAE & WI & \\
\hline Test & 1.000 & 1.000 & 1.000 & 0.001 & 0.000 & 1.000 \\
\hline Train & 1.000 & 1.000 & 1.000 & 0.000 & 0.000 & 1.000 \\
\hline
\end{tabular}

The parameters of the PSO algorithm are population size, iterations, inertia weight, damping ratio, personal and global learning coefficient, which are provided in Table 7 . The MLP neural network parameters are the hidden layers and training function as shown in Table 8. The parameter characteristics used for FS are also indicated in Table 8.

Table 7. Parameter characteristics used for PSO in this study.

\begin{tabular}{ccccccc}
\hline \multirow{2}{*}{ FIS Clusters } & Population Size & Iterations & Inertia Weight & Damping Ratio & \multicolumn{2}{c}{ Learning Coefficient } \\
\cline { 5 - 7 } & $150 \sim 350$ & $45 \sim 100$ & 1 & 0.99 & Personal & Global \\
\hline 10 & 150 & & 1 & 2 \\
\hline
\end{tabular}

Table 8. Parameter characteristics used for MLP and FE in this study.

\begin{tabular}{cc}
\hline \multicolumn{2}{c}{ Parameter characteristics used for MLP } \\
\hline Hidden Layers & Training Function \\
\hline 10 & Levenberg-Marquardt Backpropagation (LMBP) \\
\hline Number of runs & Parameter characteristics used for FS \\
\hline 3 & Number of functions (nf) \\
\hline
\end{tabular}

Before reviewing the results, it is necessary to have a comparison between the feature selection technique and other neural networks and algorithms in selecting the best inputs. A database may have a large amount of input data but, certainly, not all inputs are suitable for use in the neural network, as some of them have virtually no effect on output prediction, and some may cause network deviation. Therefore, finding the best combination is very time consuming and tedious if there is a large number of work inputs. It should be noted that the implementation of the neural network and the study of its results for this number of repetitions is impossible considering the different combinations of neural network settings. Therefore, the only way to select different input modes and settings is based on previous experiences and initial assumptions. Using the feature selection technique, with only six runs, all possible input states are checked and the best combination is determined. 


\subsubsection{Normalized Ultimate Load Prediction}

Following the prediction process, to predict the normalized ultimate load, available inputs are tested with different scenarios. Table 6 indicates the best possible input scenario to estimate the normalized ultimate load. As shown in Tables 9-11, different prediction patterns are presented by accuracy criteria (by adjusting best population and iteration). From Figures $28-30$, it is noted that the normalized ultimate load estimation is perfectly predicted by the proposed algorithm. Furthermore, as shown in the tables and graphs, the prediction accuracy in this study is $100 \%$.

Table 9. The calculated accuracy criteria for the performance of the implemented models (Iteration $=150$ ).

\begin{tabular}{|c|c|c|c|c|c|c|c|c|c|c|}
\hline \multirow{3}{*}{ Population } & \multicolumn{10}{|c|}{ Network Result } \\
\hline & \multicolumn{5}{|c|}{ Training Phase } & \multicolumn{5}{|c|}{ Testing Phase } \\
\hline & $\mathbf{R}$ & NSE & RMSE & MAE & WI & $\mathbf{r}$ & NSE & RMSE & MAE & WI \\
\hline 150 & 0.996 & 0.992 & 7.193 & 5.041 & 0.998 & 0.905 & 0.780 & 7.227 & 5.035 & 0.948 \\
\hline 250 & 0.996 & 0.992 & 7.244 & 5.270 & 0.998 & 0.907 & 0.798 & 7.199 & 5.246 & 0.951 \\
\hline 350 & 0.996 & 0.991 & 7.381 & 5.578 & 0.998 & 0.900 & 0.776 & 7.534 & 5.679 & 0.946 \\
\hline
\end{tabular}

Table 10. The calculated accuracy criteria for the performance of the implemented models (population $=250$ ).

\begin{tabular}{|c|c|c|c|c|c|c|c|c|c|c|}
\hline \multirow{3}{*}{ Iteration } & \multicolumn{10}{|c|}{ Network Result } \\
\hline & \multicolumn{5}{|c|}{ Training Phase } & \multicolumn{5}{|c|}{ Testing Phase } \\
\hline & $\mathbf{r}$ & NSE & RMSE & MAE & WI & $\mathbf{r}$ & NSE & RMSE & MAE & WI \\
\hline 100 & 0.995 & 0.990 & 7.837 & 5.751 & 0.998 & 0.882 & 0.711 & 8.333 & 5.953 & 0.934 \\
\hline 150 & 0.996 & 0.992 & 7.244 & 5.270 & 0.998 & 0.907 & 0.798 & 7.199 & 5.246 & 0.951 \\
\hline 200 & 0.995 & 0.991 & 7.504 & 5.339 & 0.998 & 0.899 & 0.762 & 7.421 & 5.250 & 0.944 \\
\hline
\end{tabular}

Table 11. The calculated accuracy criteria for the performance of the implemented models for different inputs.

\begin{tabular}{|c|c|c|c|c|c|c|c|c|c|c|c|c|}
\hline \multirow{3}{*}{$\begin{array}{l}\text { Number of } \\
\text { Inputs }\end{array}$} & \multicolumn{12}{|c|}{ Network Result } \\
\hline & \multicolumn{6}{|c|}{ Training Phase } & \multicolumn{6}{|c|}{ Testing Phase } \\
\hline & $\mathbf{R}^{2}$ & $\mathbf{r}$ & NSE & RMSE & MAE & WI & $\mathbf{R}^{2}$ & $\mathbf{r}$ & NSE & RMSE & MAE & WI \\
\hline 1 & 0.885 & 0.941 & 0.870 & 0.035 & 0.026 & 0.969 & 0.991 & 0.935 & 0.854 & 0.038 & 0.028 & 0.965 \\
\hline 2 & 0.971 & 0.985 & 0.970 & 0.018 & 0.003 & 0.993 & 0.997 & 0.978 & 0.955 & 0.022 & 0.004 & 0.989 \\
\hline 3 & 1.000 & 1.000 & 1.000 & 0.002 & 0.000 & 1.000 & 1.000 & 1.000 & 0.999 & 0.003 & 0.001 & 1.000 \\
\hline 4 & 1.000 & 1.000 & 1.000 & 0.001 & 0.000 & 1.000 & 1.000 & 1.000 & 1.000 & 0.001 & 0.000 & 1.000 \\
\hline 5 & 1.000 & 1.000 & 1.000 & 0.000 & 0.000 & 1.000 & 1.000 & 1.000 & 1.000 & 0.001 & 0.000 & 1.000 \\
\hline 6 & 0.822 & 0.996 & 0.992 & 7.244 & 5.270 & 0.998 & 0.823 & 0.907 & 0.798 & 7.199 & 5.246 & 0.951 \\
\hline
\end{tabular}

After finding the best population, the calculations to find the optimal number of repetitions are performed. According to Table 12, the optimal number of repetitions in the test phase is obtained as 150 .

According to the results obtained in the test phase, cases with 4 and 5 inputs obtain the same results. However, because it is more efficient to obtain the result with less number of inputs, the number of optimal inputs is chosen to be 4 . As shown in Table 12, the ultimate moment has the greatest impact on finding results. In addition, the distance between the bolts causes the results to be skewed and negatively impacts the results. 

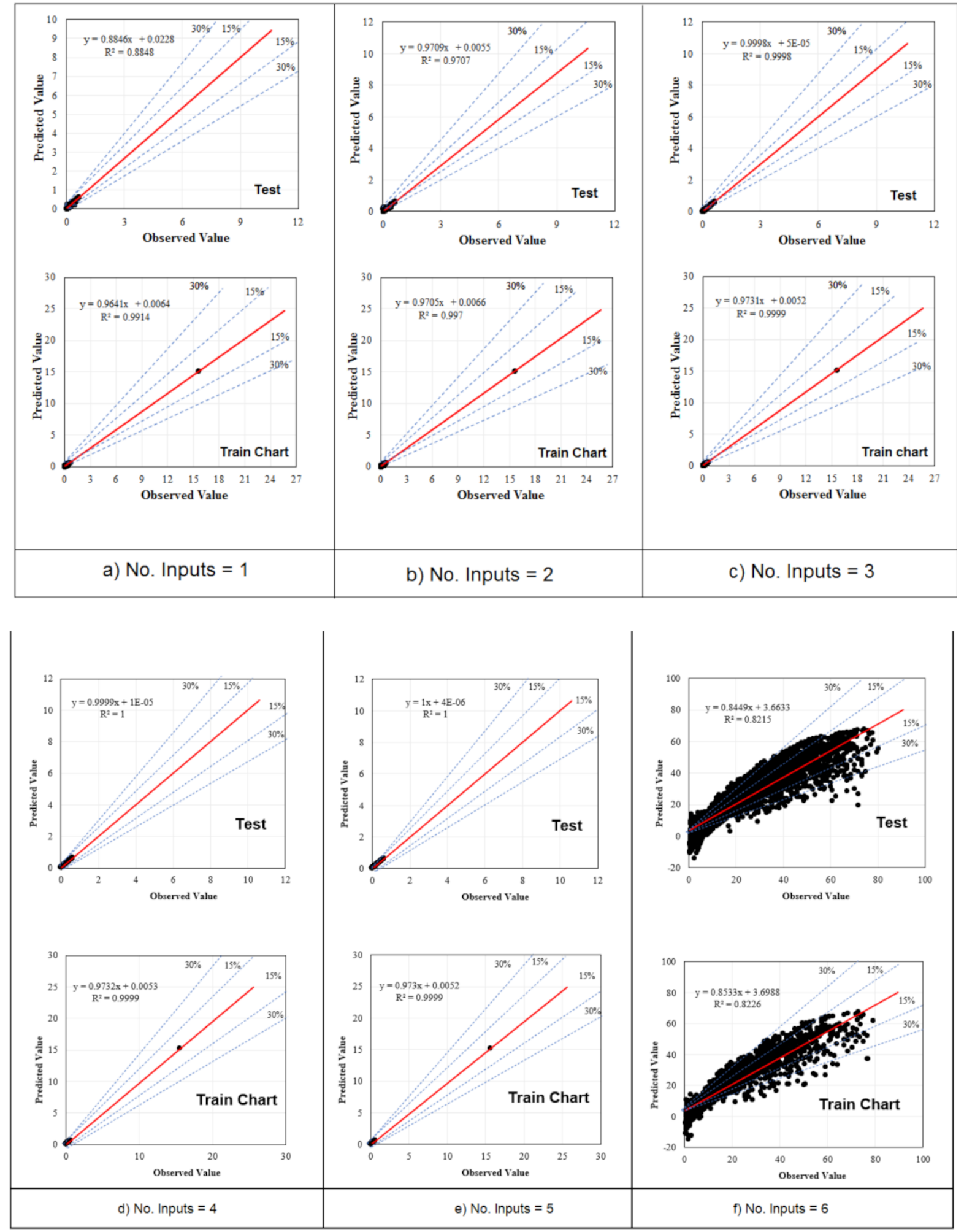

Figure 28. Comparison of the predicted and measured load: (a) One input, (b) two inputs, (c) three inputs, (d) four input, (e) five inputs, (f) six inputs through MLP-PSO-FS model. 


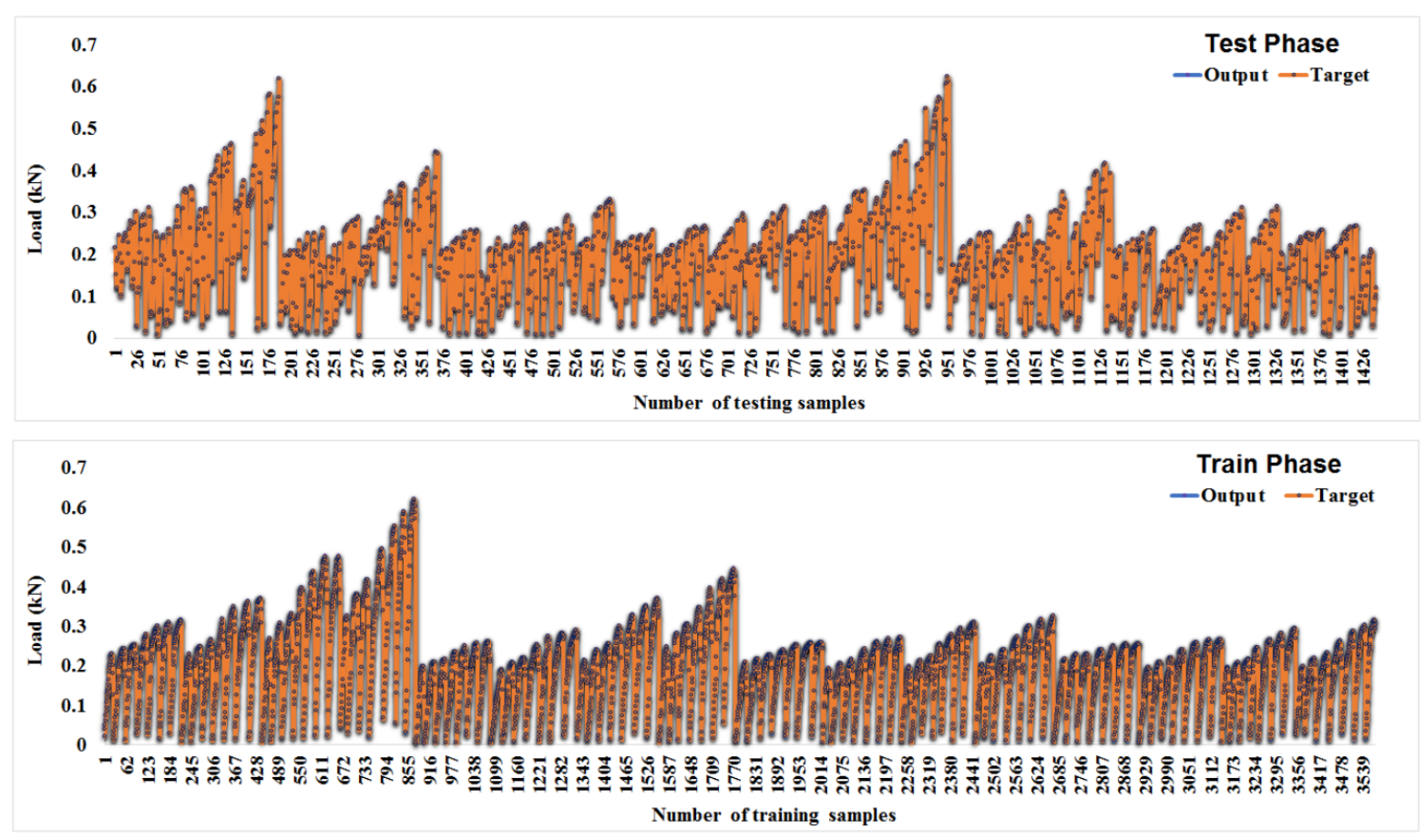

Figure 29. MLP-PSO-FS (4 inputs) prediction vs. experimental diagram: (above) train phase, (below) test phase.
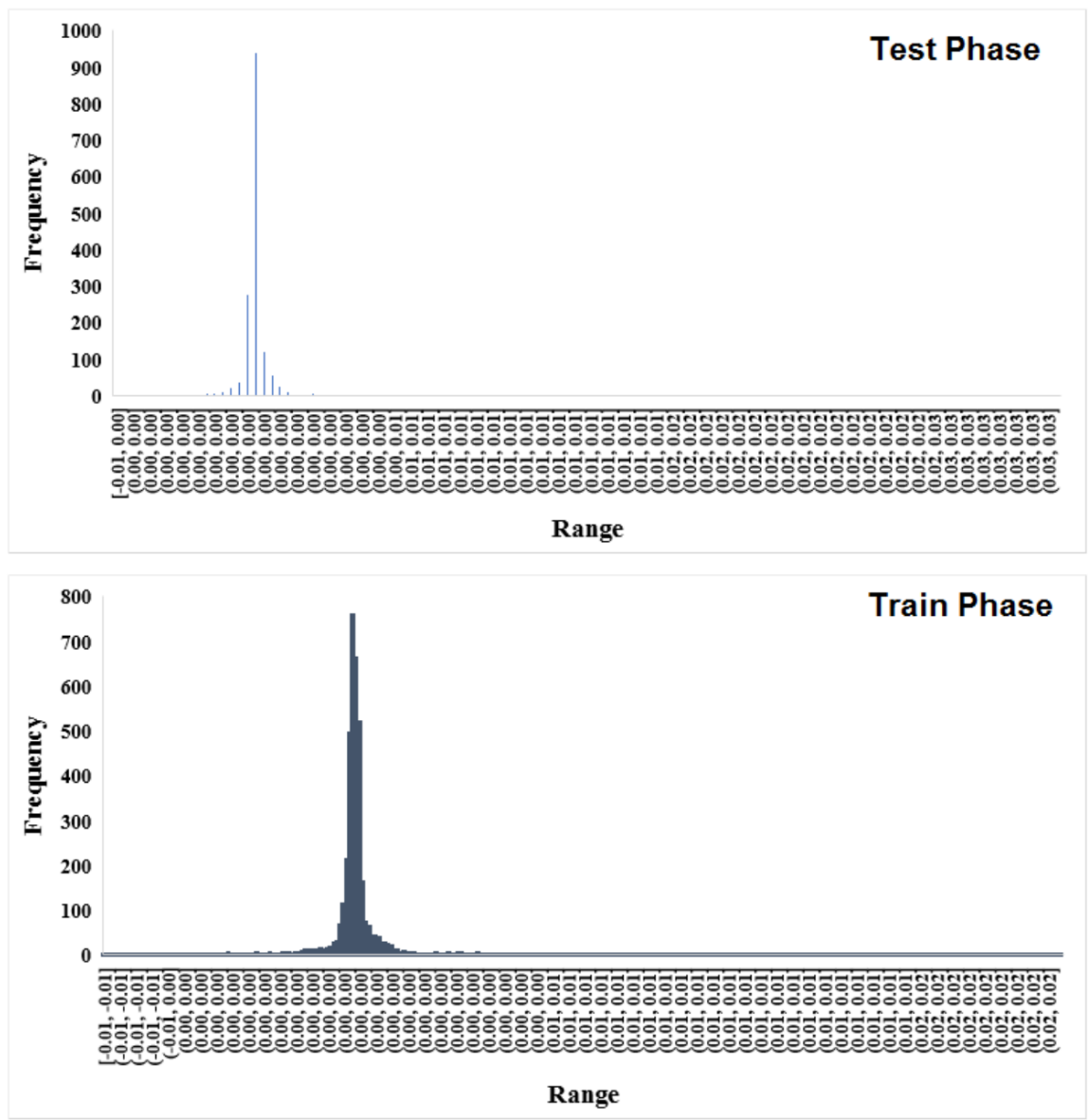

Figure 30. MLP-PSO-FS (4 inputs) Error histograms: (above) train phase, (below) test phase. 
Table 12. Most effective inputs based on feature selection.

\begin{tabular}{ccccccc}
\hline \multirow{2}{*}{ Feature } & \multicolumn{5}{c}{ Number of Inputs } \\
\cline { 2 - 6 } & $\mathbf{1}$ & $\mathbf{2}$ & $\mathbf{3}$ & $\mathbf{4}$ & $\mathbf{5}$ & $\mathbf{6}$ \\
\hline Length & & & $\mathrm{X}$ & $\mathrm{X}$ \\
\hline Bolt & $\mathrm{X}$ & $\mathrm{X}$ & $\mathrm{X}$ & $\mathrm{X}$ & $\mathrm{X}$ \\
\hline Thickness & $\mathrm{X}$ & $\mathrm{X}$ & $\mathrm{X}$ & $\mathrm{X}$ & $\mathrm{X}$ & $\mathrm{X}$ \\
\hline Deflection & & $\mathrm{X}$ & $\mathrm{X}$ & $\mathrm{X}$ & $\mathrm{X}$ \\
\hline Ult moment & $\mathrm{X}$ & & $\mathrm{X}$ & $\mathrm{X}$ \\
\hline Ult load & & & &
\end{tabular}

Figure 28 illustrates the predicted and measured load by the MLP-PSO-FS model in scatter diagrams. Figure 28a reveals the train and test phase of the model with a single input for which the performance parameters are shown in Table $11\left(R^{2}\right.$ test $=0.8848, R^{2}$ train $\left.=0.9914\right)$. Figure 28b shows the testing and training phase of the model with two inputs $\left(R^{2}\right.$ test $=0.9707$, $\mathrm{R}^{2}$ train $=0.997$ ). According to this procedure, it is obvious that the MLP-PSO-FS model shows acceptable performance where the number of inputs is increased to five inputs. Nevertheless, the MLP-PSO-FS model with six inputs does not perform well enough in comparison with other models. Figure 28d,e represents the best-achieved predictions amongst other models, although there is a little difference between these two models in the prediction capability which is shown in Table 11. As can be seen, some improvements in the performance of the MLP is captured by utilizing the PSO algorithm in such a way that the $r$ and $R^{2}$ values are increased and the RMSE value is decreased. The testing phase is also improved with respect to the MLP-PSO-FS model.

Figure 29 indicates the capability of the models in the testing phase to predict each of the measured values of the test samples. As can be observed, both of the MLP-PSO-FS with four input models are capable of predicting most of the test samples closely. As shown in Table 9 and Figure 30, the best performance parameters for the PSO-FS neural network are $\mathrm{RMSE}=0.001, \mathrm{r}=1.000, \mathrm{R}^{2}=1.000, \mathrm{NSE}=1.000, \mathrm{MAE}=0$, and $\mathrm{WI}=1.000$. Considering that the best result for RMSE is the lowest result and for $r$, the best positive correlation coefficient is 1 , then numbers closer to 1 are considered better results. Additionally, for NSE and MAE, smaller results and for WI, larger results, indicate better performance.

\subsubsection{Deflection Prediction}

Firstly, the best number of populations needs to be found by considering a constant number of repetitions equal to 45 . In Table 13, the population of 250 is identified as the best result in the test phase.

Table 13. The calculated accuracy criteria for the performance of the implemented models (iteration $=45$ ).

\begin{tabular}{|c|c|c|c|c|c|c|c|c|c|c|}
\hline \multirow{3}{*}{ Population } & \multicolumn{10}{|c|}{ Network Result } \\
\hline & \multicolumn{5}{|c|}{ Training Phase } & \multicolumn{5}{|c|}{ Testing Phase } \\
\hline & $\mathbf{r}$ & NSE & RMSE & MAE & WI & $\mathbf{r}$ & NSE & RMSE & MAE & WI \\
\hline 150 & 0.948 & 0.886 & 5.434 & 3.186 & 0.972 & 0.933 & 0.852 & 6.200 & 3.567 & 0.964 \\
\hline 250 & 0.942 & 0.874 & 5.706 & 3.409 & 0.970 & 0.943 & 0.878 & 5.702 & 1.457 & 0.970 \\
\hline 350 & 0.944 & 0.879 & 5.594 & 3.354 & 0.971 & 0.936 & 0.856 & 6.093 & 3.623 & 0.966 \\
\hline
\end{tabular}

After finding the best population, the calculations to find the optimal number of repetitions are carried out. According to Table 14, the optimal number of repetitions in the test phase is 45 . 
Table 14. The calculated accuracy criteria for the performance of the implemented models (population $=250$ ).

\begin{tabular}{|c|c|c|c|c|c|c|c|c|c|c|}
\hline \multirow{3}{*}{ Iteration } & \multicolumn{10}{|c|}{ Network Result } \\
\hline & \multicolumn{5}{|c|}{ Training Phase } & \multicolumn{5}{|c|}{ Testing Phase } \\
\hline & $\mathbf{r}$ & NSE & RMSE & MAE & WI & $\mathbf{r}$ & NSE & RMSE & MAE & WI \\
\hline 45 & 0.942 & 0.874 & 5.706 & 3.409 & 0.970 & 0.943 & 0.878 & 5.702 & 1.457 & 0.970 \\
\hline 75 & 0.948 & 0.886 & 5.415 & 3.235 & 0.972 & 0.932 & 0.848 & 6.297 & 3.583 & 0.964 \\
\hline 100 & 0.947 & 0.884 & 5.492 & 3.137 & 0.972 & 0.938 & 0.862 & 5.936 & 3.310 & 0.967 \\
\hline
\end{tabular}

Following finding the best parameters for the neural network, the optimal input combination is found through the feature selection technique. As mentioned earlier, this technique does not require testing all possible combinations, and it is sufficient to test them only once for each set of $\mathrm{k}$ members. For example, if the best combination of inputs with four members is required to be determined, the network needs to be run only once and the value of nf needs to be set to six. Additionally, the network of six inputs that has the most impact on the answer should be selected. In Table 15 and Figure 31, the best value of $\mathrm{k}$ is specified.

Table 15. The calculated accuracy criteria for the performance of the implemented models for different inputs.

\begin{tabular}{|c|c|c|c|c|c|c|c|c|c|c|c|c|}
\hline \multirow{3}{*}{$\begin{array}{l}\text { Number of } \\
\text { Inputs }\end{array}$} & \multicolumn{12}{|c|}{ Network Result } \\
\hline & \multicolumn{6}{|c|}{ Training Phase } & \multicolumn{6}{|c|}{ Testing Phase } \\
\hline & $\mathbf{R}^{2}$ & $\mathbf{r}$ & NSE & RMSE & MAE & WI & $\mathbf{R}^{2}$ & $\mathbf{r}$ & NSE & RMSE & MAE & WI \\
\hline 1 & 0.493 & 0.702 & 0.046 & 12.000 & 8.788 & 0.807 & 0.496 & 0.704 & 0.097 & 12.504 & 3.893 & 0.803 \\
\hline 2 & 0.783 & 0.885 & 0.723 & 7.993 & 5.684 & 0.936 & 0.782 & 0.884 & 0.734 & 7.889 & 2.437 & 0.937 \\
\hline 3 & 0.853 & 0.924 & 0.828 & 6.511 & 4.034 & 0.959 & 0.805 & 0.897 & 0.758 & 7.626 & 1.914 & 0.943 \\
\hline 4 & 0.892 & 0.944 & 0.880 & 5.608 & 3.342 & 0.971 & 0.857 & 0.926 & 0.831 & 6.512 & 1.610 & 0.960 \\
\hline 5 & 0.897 & 0.947 & 0.885 & 5.441 & 3.242 & 0.972 & 0.870 & 0.933 & 0.839 & 6.279 & 1.545 & 0.963 \\
\hline 6 & 0.888 & 0.942 & 0.874 & 5.706 & 3.409 & 0.970 & 0.890 & 0.943 & 0.878 & 5.702 & 1.457 & 0.970 \\
\hline
\end{tabular}

As shown in Table 16, the results are almost the same for four or more inputs. As it is clear, the ultimate moment has the smallest effect and the effect of the other parameters is almost the same. In Figures 31-33, the diagrams related to the six compounds are presented.

Table 16. Most effective inputs based on feature selection.

\begin{tabular}{ccccccc}
\hline \multirow{2}{*}{ Feature } & $\mathbf{5}$ & Number of Inputs \\
\cline { 2 - 6 } & $\mathbf{1}$ & $\mathbf{2}$ & $\mathbf{3}$ & $\mathbf{4}$ & $\mathbf{5}$ & $\mathbf{6}$ \\
\hline Length & & $\mathrm{X}$ & $\mathrm{X}$ & $\mathrm{X}$ & $\mathrm{X}$ \\
\hline Bolt & & $\mathrm{X}$ & $\mathrm{X}$ & $\mathrm{X}$ & $\mathrm{X}$ \\
\hline Thickness & & $\mathrm{X}$ & $\mathrm{X}$ & $\mathrm{X}$ \\
\hline (M/ZY.Fy) & $\mathrm{X}$ & $\mathrm{X}$ & $\mathrm{X}$ & $\mathrm{X}$ \\
\hline Ult moment & $\mathrm{X}$ & $\mathrm{X}$ & & $\mathrm{X}$ & $\mathrm{X}$ \\
\hline Ult load & & & & & \\
\hline
\end{tabular}




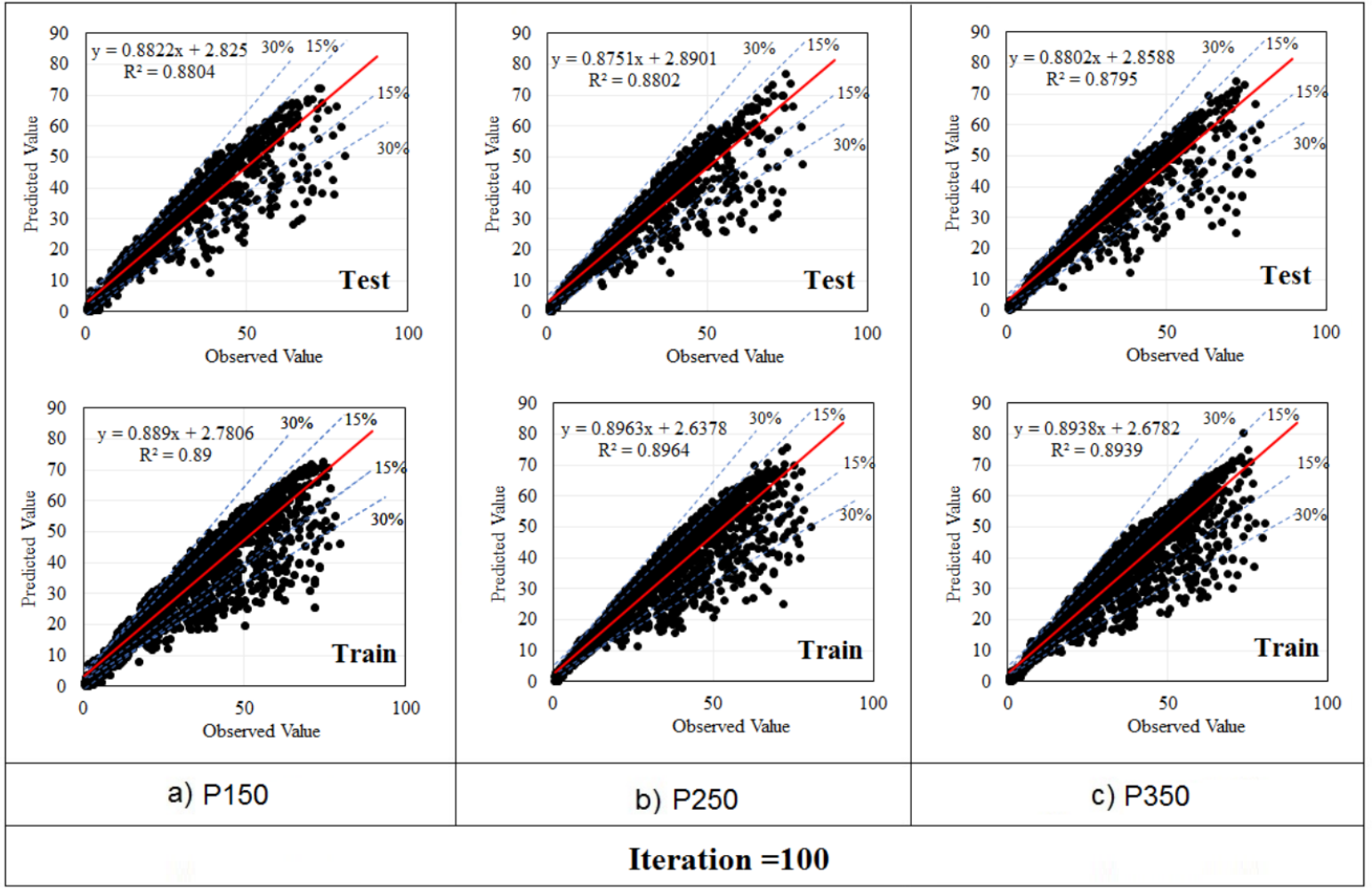

Figure 31. MLP-PSO-FS regression charts (iteration = 100): (a) P150, (b) P250, (c) P350.

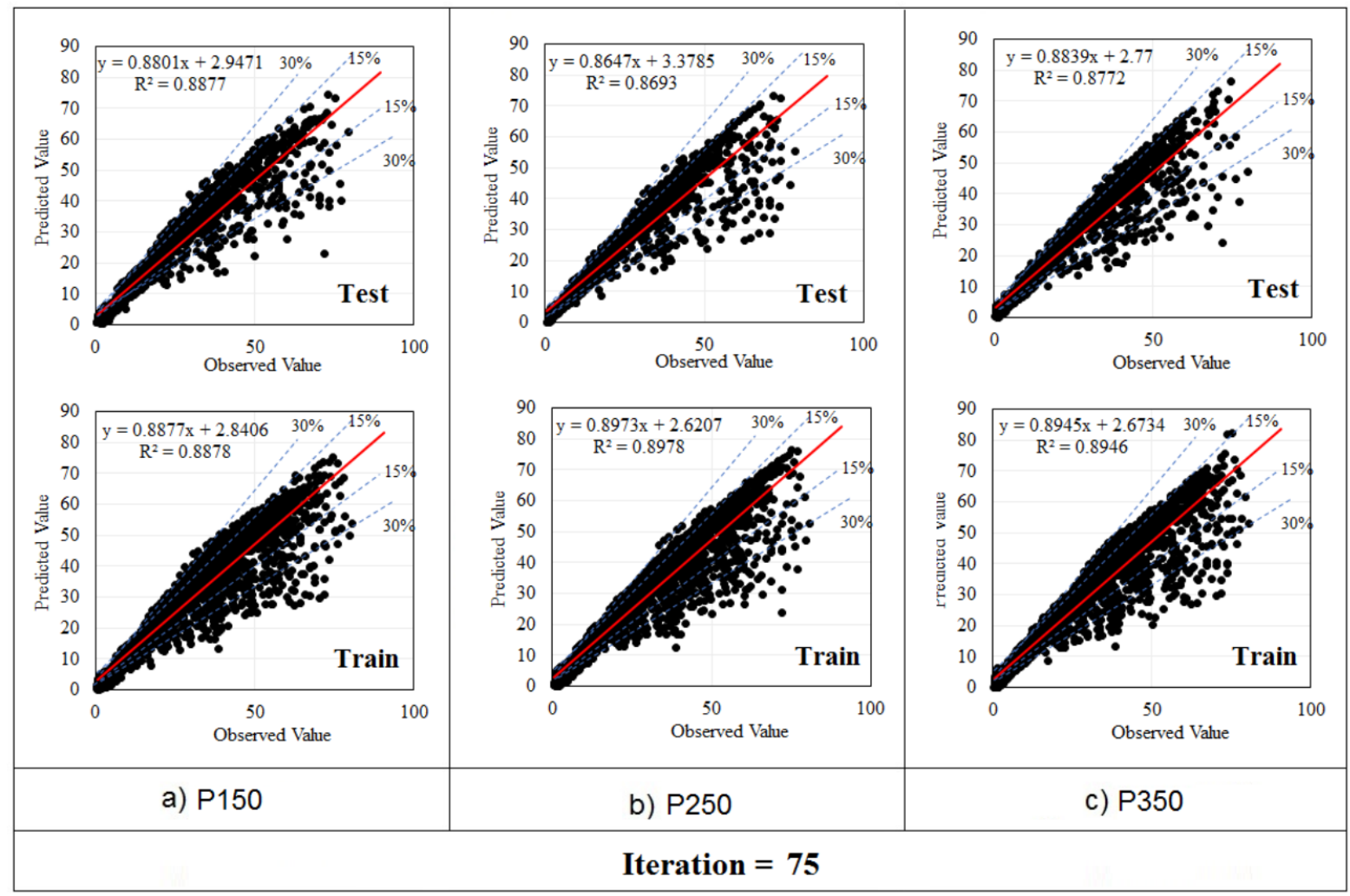

Figure 32. MLP-PSO-FS regression charts (iteration = 75): (a) P150, (b) P250, (c) P350. 


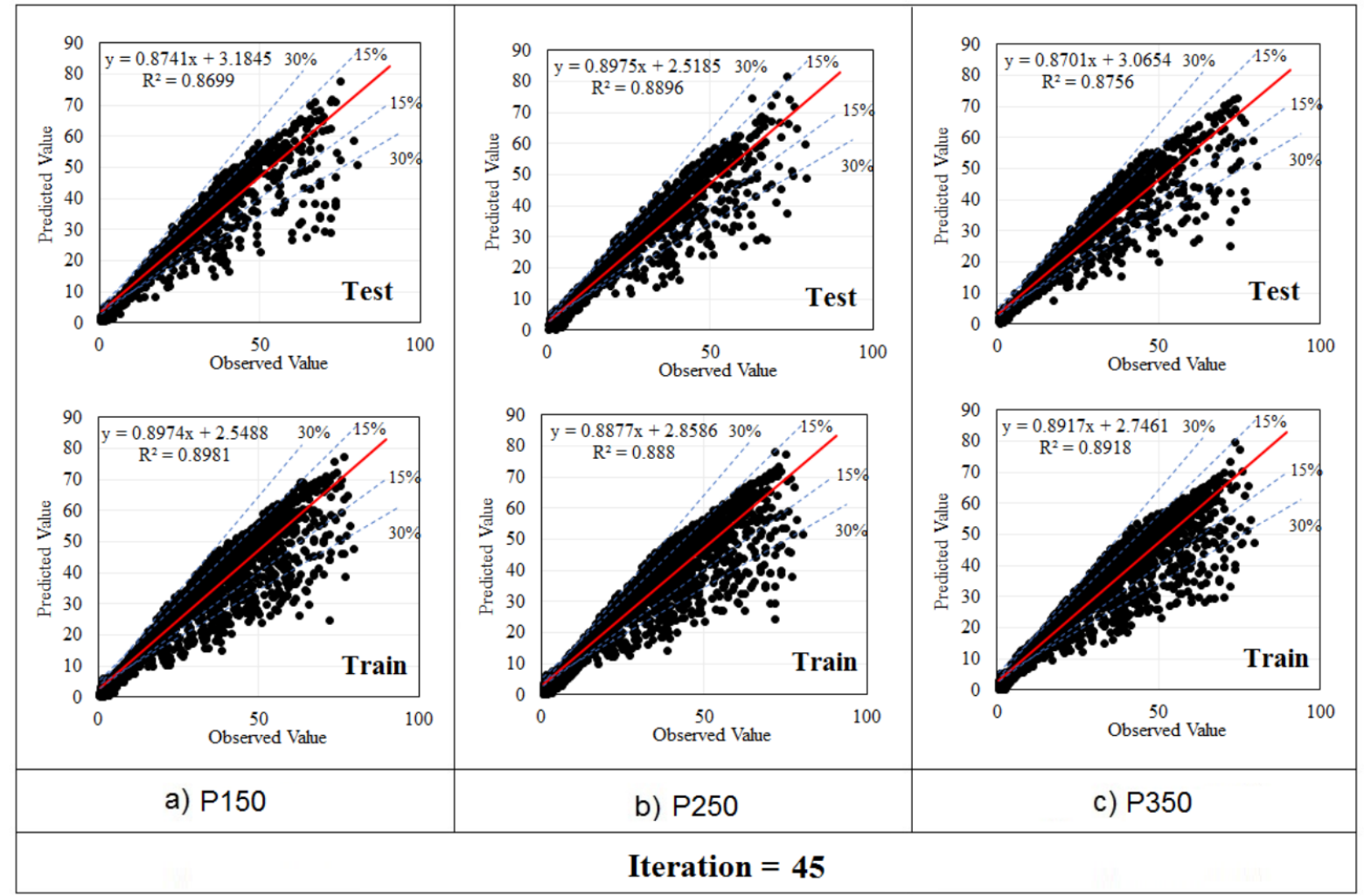

Figure 33. MLP-PSO-FS regression charts (iteration = 45): (a) P150, (b) P250, (c) P350.

Figures 31-33 demonstrate the results of the MLP-PSO-FS models in the prediction of the deflection. It is obvious that predicting the deflection is faced with more challenges than flexural load prediction. Figure 31 illustrates the training and testing phase of the MLP-PSO-FS model with 100 iterations. Performance indices of the model in Figure 31a with 150 show that the population is noticeably better than the other two populations $\left(R^{2}\right.$ test $=0.8804, R^{2}$ train $\left.=0.89\right)$. Figure 32 illustrates optimal regression against two other population with 75 iterations $\left(R^{2}\right.$ test $=0.8772, R^{2}$ train $\left.=0.8946\right)$. Figure 33 illustrates that the case with 250 population represents an enhanced model in comparison with other population models with 45 iterations $\left(R^{2}\right.$ test $=0.8896, R^{2}$ train $\left.=0.888\right)$. As can be realized, the MLP-PSO-FS model performs better with 100 iterations in the training phase. The testing phase is also improved in the 45-iteration model. Most importantly, the close values of performance indices in the training and testing phases confirm the high reliability of the models.

The capability of the models in the prediction of each test sample is indicated in Figure 34. A significantly close prediction of the models and the better performance of the MLP-PSO model can be seen in this figure. As shown in Table 13 and Figure 35, the best performance parameters for the PSO-FS neural network are RMSE $=5.702, \mathrm{r}=0.943$, $\mathrm{R}^{2}=0.890, N S E=0.878, M A E=1.457$, and $W I=0.970$. The best result for RMSE is the minor value, and for $r$, the best positive correlation coefficient is 1 . The numbers closer to 1 are considered better results. For NSE and MAE, smaller results and for WI, larger results indicate better performance. 

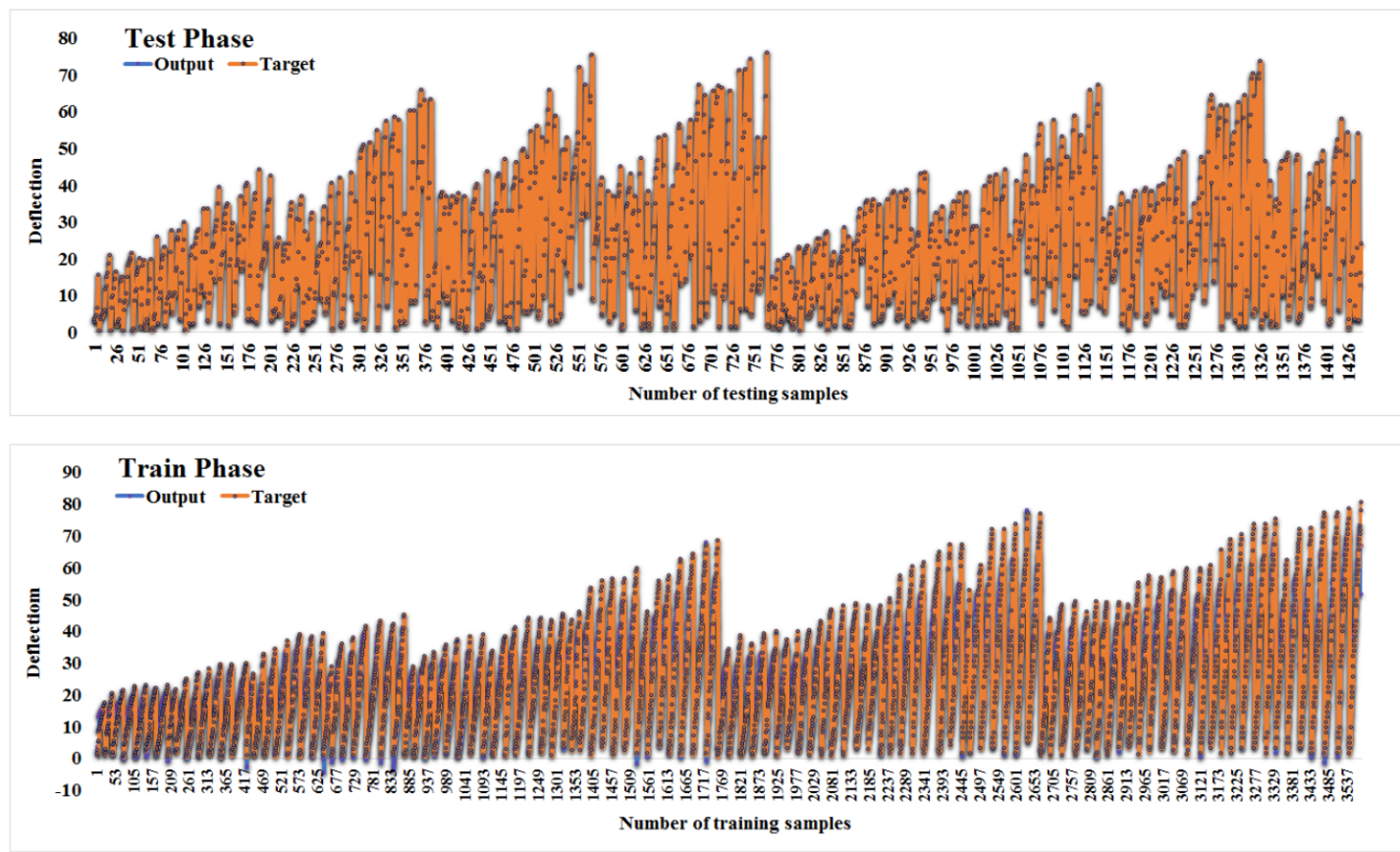

Figure 34. MLP-PSO-FS (6 inputs) prediction vs. experimental diagram: (above) train phase, (below) test phase.
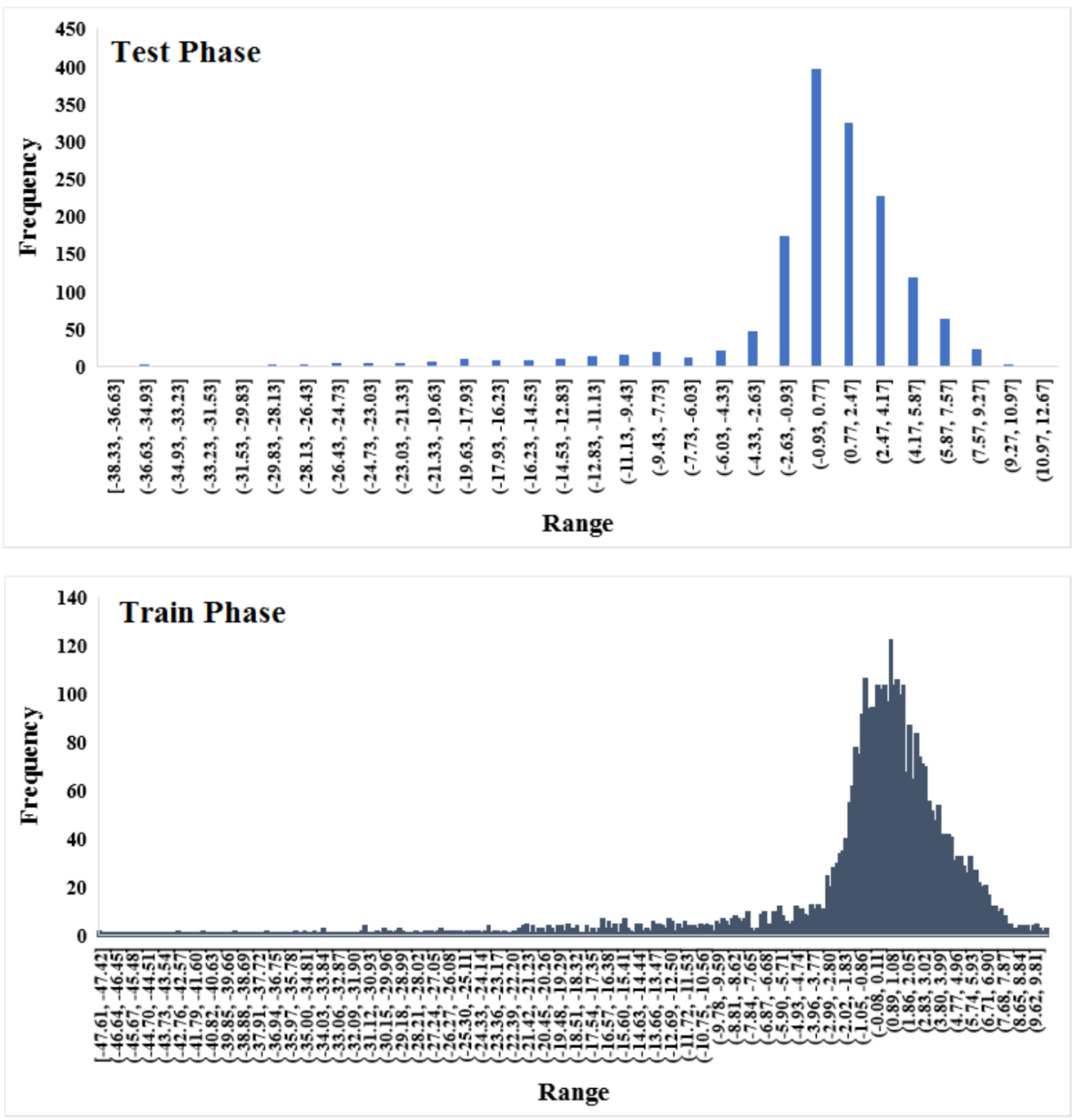

Figure 35. PSO-FS (6 inputs) error histograms: (above) train phase, (below) test phase. 


\section{Conclusions}

In this study, in order to investigate the flexural performance of the CFS upright frames strengthened by an innovative reinforcement method, FEM models were developed in ABAQUS and verified by experimental test data. Then, in a parametric study, uprights with different thicknesses and lengths and reinforcement spacing were modeled and analyzed under flexural loading, and the results were obtained. Using ABAQUS, FEM results indicated that with closer reinforcements, the models show a stiffened behavior. According to the literature, FEM is capable of simulating CFS section structural behavior. Additionally, in this study, the MLP-PSO hybrid neural network by combining the evolutionary feature selection technique was used to predict some major characteristics of CFS upright frames, such as "flexural strength" and "deflection". The feature selection technique was used to avoid trying all possible input modes and wasting time. It provided the best possible input combination that may be overlooked in other methods. The neural network results illustrated noticeable accuracy and a fascinating prediction ability of the MLP algorithm along with the feature selection technique, which has compatibility with the literature.

According to the FEM results, both in major and minor axis simulations, all models indicated a unique behavior with respect to length/thickness variation. The thicker models showed higher flexural capacity, especially those with shorter lengths. Moreover, taller uprights faced capacity loss due to buckling. This deficiency was somehow addressed by the proposed reinforcements. The proposed fasteners played a noticeable role as reinforcement not only in longer uprights, but also in thinner ones. By reducing the fastener spacing, the ultimate load of the models was increased.

According to the analytical study, the FEM results were verified and proved to be authenticated through the training phase of the analytical analysis. The predictions were performed for both the deflection value and ultimate flexural load, and the accuracy of the prediction was evaluated. Employing a hybrid neural network based on the featureselection technique successfully predicted the normalized ultimate load and the deflection.

Author Contributions: Conceptualization, E.T. and B.S.; methodology, E.T. and B.S.; software, E.T.; validation, E.T.; formal analysis, E.T.; investigation, E.T.; resources, E.T., S.E.F., Y.Z., B.S.; data curation, E.T.; writing—original draft preparation, E.T.; writing—review and editing, E.T., S.E.F., Y.Z., B.S.; visualization, E.T.; supervision, E.T., B.S.; project administration, E.T., B.S.; funding acquisition, E.T., B.S. All authors have read and agreed to the published version of the manuscript.

Funding: The research was funded by the R\&D contract budget of Western Sydney University. The materials for laboratory testing were provided by Dexion Australia.

Institutional Review Board Statement: Not applicable.

Informed Consent Statement: Not applicable.

Data Availability Statement: Restrictions apply to the availability of these data. Data was obtained from testing on specimens of Dexion Australia and are available the authors with the permission of Dexion Australia.

Acknowledgments: The authors would like to acknowledge the contribution by Dexion Australia in supporting this study.

Conflicts of Interest: The authors declare no conflict of interest.

\section{References}

1. Shariati, M.; Faegh, S.S.; Mehrabi, P.; Bahavarnia, S.; Zandi, Y.; Masoom, D.R.; Toghroli, A.; Trung, N.T.; Salih, M.N.A. Numerical study on the structural performance of corrugated low yield point steel plate shear walls with circular openings. Steel Compos. Struct. 2019, 33, 569-581.

2. Zhao, X.; Wang, T.; Chen, Y.; Sivakumaran, K.S. Flexural behaviour of steel storage rack beam-to-upright connections. J. Constr. Steel Res. 2014, 99, 161-175. [CrossRef]

3. Firouzianhaji, A.; Usefi, N.; Samali, B.; Mehrabi, P. Shake Table Testing of Standard Cold-Formed Steel Storage Rack. Appl. Sci. 2021, 11, 1821. [CrossRef]

4. Put, B.M.; Pi, Y.L.; Trahair, N.S. Bending and torsion of cold-formed channel beams. J. Struct. Eng. 1999, 125, 540-546. [CrossRef] 
5. Wang, L.; Young, B. Behavior of cold-formed steel built-up sections with intermediate stiffeners under bending. I: Tests and numerical validation. J. Struct. Eng. 2015, 142, 04015150. [CrossRef]

6. Calderoni, B.; De Martino, A.; Formisano, L.; Fiorino, L. Cold formed steel beams under monotonic and cyclic loading: Experimental investigation. J. Constr. Steel Res. 2009, 65, 219-227. [CrossRef]

7. Wang, H.; Zhang, Y. Experimental and numerical investigation on cold-formed steel C-section flexural members. J. Constr. Steel Res. 2009, 65, 1225-1235. [CrossRef]

8. Taheri, E.; Firouzianhaji, A.; Usefi, N.; Mehrabi, P.; Ronagh, H.; Samali, B. Investigation of a Method for Strengthening Perforated Cold-Formed Steel Profiles under Compression Loads. Appl. Sci. 2019, 9, 5085. [CrossRef]

9. Taheri, E.; Firouzianhaji, A.; Mehrabi, P.; Vosough Hosseini, B.; Samali, B. Experimental and Numerical Investigation of a Method for Strengthening Cold-Formed Steel Profiles in Bending. Appl. Sci. 2020, 10, 3855. [CrossRef]

10. Visy, D.; Szedlák, M.; Geleji, B.B.; Ádány, S. Flexural buckling of thin-walled lipped channel columns with slotted webs: Numerical and analytical studies. Eng. Struct. 2019, 197, 109399. [CrossRef]

11. Nandini, P.; Kalyanaraman, V. Strength of cold-formed lipped channel beams under interaction of local, distortional and lateral torsional buckling. Thin Walled Struct. 2010, 48, 872-877. [CrossRef]

12. Chu, X.; Kettle, R.; Li, L. Lateral-torsion buckling analysis of partial-laterally restrained Thin Walled channel-section beams. J. Constr. Steel Res. 2004, 60, 1159-1175. [CrossRef]

13. Ye, J.; Hajirasouliha, I.; Becque, J.; Pilakoutas, K. Development of more efficient cold-formed steel channel sections in bending. Thin Walled Struct. 2016, 101, 1-13. [CrossRef]

14. Gilbert, B.P.; Savoyat, T.J.M.; Teh, L.H. Self-shape optimisation application: Optimisation of cold-formed steel columns. Thin Walled Struct. 2012, 60, 173-184. [CrossRef]

15. Shariati, M.; Trung, N.T.; Wakil, K.; Mehrabi, P.; Safa, M.; Khorami, M. Estimation of moment and rotation of steel rack connection using extreme learning machine. Steel Compos. Struct. 2019, 31, 427-435.

16. Shariati, M.; Mafipour, M.S.; Mehrabi, P.; Ahmadi, M.; Wakil, K.; Trung, N.T.; Toghroli, A. Prediction of concrete strength in presence of furnace slag and fly ash using Hybrid ANN-GA (Artificial Neural Network-Genetic Algorithm). Smart Struct. Syst. 2020, 25, 183-195.

17. Shariati, M.; Mafipour, M.S.; Mehrabi, P.; Bahadori, A.; Zandi, Y.; Salih, M.N.A.; Nguyen, H.; Dou, J.; Song, X.; Poi-Ngian, S. Application of a Hybrid Artificial Neural Network-Particle Swarm Optimization (ANN-PSO) Model in Behavior Prediction of Channel Shear Connectors Embedded in Normal and High-Strength Concrete. Appl. Sci. 2019, 9, 5534. [CrossRef]

18. Hornik, K.; Stinchcombe, M.; White, H. Multilayer feedforward networks are universal approximators. Neural Netw. 1989, 2, 359-366. [CrossRef]

19. Koopialipoor, M.; Fahimfar, A.; Ghaleini, E.; Momenzadeh, M.; Jahed Armaghani, D. Development of a new hybrid ANN for solving a geotechnical problem related to tunnel boring machine performance. Eng. Comput. 2020, 36, 1-13. [CrossRef]

20. Shariati, M.; Mafipour, M.S.; Mehrabi, P.; Zandi, Y.; Dehghani, D.; Bahadori, A.; Shariati, A.; Trung, N.T.; Shek, P. Application of Extreme Learning Machine (ELM) and Genetic Programming (GP) to design steel-concrete composite floor systems at elevated temperatures. Steel Compos. Struct. 2019, 33, 319.

21. Firouzianhaji, A. The Effect of Connection Flexibility on the Seismic Performance of Industrial Racking Systems. Ph.D. Thesis, UTS, Sydney, Australia, 2016.

22. Usefi, N.; Sharafi, P.; Ronagh, H. Numerical models for lateral behaviour analysis of cold-formed steel framed walls: State of the art, evaluation and challenges. Thin Walled Struct. 2019, 138, 252-285. [CrossRef]

23. Usefi, N.; Ronagh, H.; Sharafi, P. Numerical modelling and design of hybrid cold-formed steel wall panels. Thin Walled Struct. 2020, 157, 107084. [CrossRef]

24. Kasaeian, S.; Usefi, N.; Ronagh, H.; Dareshiry, S. Seismic performance of CFS strap-braced walls using capacity-based design approach. J. Constr. Steel Res. 2020, 174, 106317. [CrossRef]

25. Mehrabi, P.; Shariati, M.; Kabirifar, K.; Jarrah, M.; Rasekh, H.; Thoi Trung, N.; Shariati, A.; Jahandari, S. Effect of pumice powder and nano-clay on the strength and permeability of fiber-reinforced pervious concrete incorporating recycled concrete aggregate. Constr. Build. Mater. 2021, 287, 122652. [CrossRef]

26. Shariati, M.; Mafipour, M.S.; Mehrabi, P.; Shariati, A.; Toghroli, A.; Thoi Trung, N.; Salih, M.N.A. A novel approach to predict shear strength of tilted angle connectors using artificial intelligence techniques. Eng. Comput. 2020, 1-21. [CrossRef]

27. Shahgoli, A.F.; Zandi, Y.; Heirati, A.; Khorami, M.; Mehrabi, P.; Petkovic, D. Optimisation of propylene conversion response by neuro-fuzzy approach. Int. J. Hydromechatron. 2020, 3, 228-237. [CrossRef]

28. Toghroli, A.; Mehrabi, P.; Shariati, M.; Trung, N.; Jahandari, S.; Rasekh, H. Evaluating the use of recycled concrete aggregate and pozzolanic additives in fiber-reinforced pervious concrete with industrial and recycled fibers. Constr. Build. Mater. 2020, 252, 118997. [CrossRef]

29. Armaghani, D.J.; Hasanipanah, M.; Bakhshandeh Amnieh, H.; Bui, D.T.; Mehrabi, P.; Khorami, M. Development of a novel hybrid intelligent model for solving engineering problems using GS-GMDH algorithm. Eng. Comput. 2019, 36, 1379-1391. [CrossRef]

30. Mehrabi, P.; Honarbari, S.; Rafiei, S.; Jahandari, S.; Alizadeh Bidgoli, M. Seismic response prediction of FRC rectangular columns using intelligent fuzzy-based hybrid metaheuristic techniques. J. Ambient Intell. Humaniz. Comput. 2021, 1-19. [CrossRef]

31. Liao, X.; Khandelwal, M.; Yang, H.; Koopialipoor, M.; Murlidhar, B.R. Effects of a proper feature selection on prediction and optimization of drilling rate using intelligent techniques. Eng. Comput. 2020, 36, 499-510. [CrossRef] 
32. Yaseen, Z.M.; Deo, R.C.; Hilal, A.; Abd, A.M.; Bueno, L.C.; Salcedo-Sanz, S.; Nehdi, M.L. Predicting compressive strength of lightweight foamed concrete using extreme learning machine model. Adv. Eng. Softw. 2018, 115, 112-125. [CrossRef]

33. Keshtegar, B.; Bagheri, M.; Yaseen, Z.M. Shear strength of steel fiber-unconfined reinforced concrete beam simulation: Application of novel intelligent model. Compos. Struct. 2019, 212, 230-242. [CrossRef]

34. Al-Musawi, A.A.; Alwanas, A.A.H.; Salih, S.Q.; Ali, Z.H.; Tran, M.T.; Yaseen, Z.M. Shear strength of SFRCB without stirrups simulation: Implementation of hybrid artificial intelligence model. Eng. Comput. 2020, 36, 1-11. [CrossRef]

35. Sanikhani, H.; Deo, R.C.; Yaseen, Z.M.; Eray, O.; Kisi, O. Non-tuned data intelligent model for soil temperature estimation: A new approach. Geoderma 2018, 330, 52-64. [CrossRef]

36. Broomhead, D.S.; Lowe, D. Radial Basis Functions, Multi-Variable Functional Interpolation and Adaptive Networks; RSRE-MEMO-4148; Royal Signals and Radar Establishment Malvern: Worcestershire, UK, 1998. 